\title{
Social Inequality in Student Expectations and Higher \\ Education Enrollment - A Comparison between the United States and Germany
}

\author{
Andrea G. Forster ${ }^{\mathrm{a},} \quad$ Anna Katyn Chmielewski ${ }^{\mathrm{b}}$ \\ Herman G. van de Werfhorst ${ }^{\mathrm{a}}$
}

October 5, 2020

* Corresponding author: a.g.forster@uva.nl

a Amsterdam Institute for Social Science Research, University of Amsterdam

b Ontario Institute for Studies in Education, University of Toronto

Work in progress - please do not cite or circulate without permission of the authors 


\section{Introduction}

Inequality of opportunity (IEO) is a concern in most societies: students from lower socioeconomic status (SES) reach on average lower levels of education than students from more advantaged backgrounds (Shavit and Blossfeld, 1993; Breen and Jonsson, 2005). While most countries have been experiencing educational expansion in the last decades, with all students obtaining relatively higher and higher degrees, social inequalities in educational attainment have persisted especially in the access to higher education (Reimer and Pollak, 2010; Duru-Bellat et al., 2008; Alon, 2009). As a reaction, in the United States, policy makers and the public alike are demanding broadened access to college. Policy programs such as GEAR UP have been put into place to help especially low income students to enter higher education. Student expectations have been identified as a key factor in this endeavor (US Department of Education, 2019). Students are not supposed to be satisfied with a high school diploma but everyone should aim to go to college (Rosenbaum, 2001). The idea is that if students have high expectations for their education, they will make more ambitious choices and higher attainment will follow suit.

Educational expectations also feature prominently in sociological theories of status attainment (Sewell et al., 1969; Sewell and Shah, 1968; Sewell et al., 2004), where they are seen as an important mechanism behind inequality in educational attainment. As a consequence, the relationship between social origin and the development of expectations has been studied extensively (Baird et al., 2008; Morgan, 1998; Buchmann and Dalton, 2002; Kao and Tienda, 1998; Bozick et al., 2010). However, the relationship between expectations and educational attainment as received less attention. Sociological theories have assumed a very close link between expectations and educational attainment (Sewell et al., 1969). Empirical research has mostly compared average levels of expectations to college graduation rates on an aggregate level (e.g., Buchmann and Park, 2009; Parker et al., 2016; Jerrim, 2014). However, how expectations are translated into attainment on the individual level remains largely unknown.

If educational attainment indeed follows directly from student expectations, then raising expectations of low-SES students would be a suitable policy measure to decrease educational 
inequality. However, while student expectations have strongly increased in the last years, college enrollment has rather stagnated (Baird et al., 2008; Reynolds et al., 2006). This is casting some doubt on the strength of the relationship between expectations and attainment. In other words, it remains contested whether it is enough to encourage students to aim high or whether additional barriers exist that prevent students from realizing their high expectations.

Additionally, inequality of opportunity can be conceptualized as consisting of two distinct processes: low-SES students show lower levels of school performance and, therefore, reach lower levels of education but they also make different decisions about education even when their school achievement is relatively similar (secondary effects) (Boudon, 1974; Jackson, 2013). So far, secondary effects of social origin have most often been studied as residual inequality once differences in student achievement are taken into account (Jackson, 2013). Less research has been done on the specific factors that drive secondary effects. Student expectations are one possible factor behind these differential choices made by students of different social origin.

We investigate student expectations as a mechanism of educational inequality and, thereby, place a particular focus on the link between expectations and attainment. The main question is how likely students are to realize their expectations by translating them into college enrollment. We argue that low-SES students have a lower chance of realizing their expectations than more advantaged students.

Furthermore, we look at these processes mostly net of achievement differences in an attempt to uncover how expectations contribute to secondary effects of social origin. The question, thereby, is whether differential expectations explain why students of different SES make different educational choices even if their academic achievement is similar. However, we also decompose the relationship between social origin and higher education enrollment into different components that can be attributed to achievement and expectations respectively.

Finally, we investigate whether different national educational education systems and achievement cultures affect student expectations and their realization by looking at country 
differences. There has been research on the link between expectations and educational attainment that is either longitudinal for the United States (e.g., Hanson, 1994; Reynolds et al., 2006) or cross-sectional comparing different educational systems (Buchmann and Park, 2009; Parker et al., 2016; Jerrim, 2014). To our knowledge, there has not been a comparative, longitudinal assessment of the realization of student expectations to this date. we choose two countries with strongly different educational systems and culture - the United States and Germany — to investigate whether the contribution of expectations to inequality differs depending on the institutional setting in which students operate. we use nationally-representative longitudinal data for the two countries to follow individual students from age 15 into early adulthood and connect educational expectations to inequalities in higher education enrollment.

We find that the level of expectations and their translation to higher education enrollment is indeed stratified by socioeconomic status. Contrary to our expectations we do not find country differences in the probability to realize expectations. However, we see that expectations overall play a larger role in explaining educational inequality in the US than in Germany where achievement differences are a more prominent driver of IEO.

\section{Theoretical Framework and Context}

This study investigates student expectations as a mechanism behind educational inequality and, thereby, the processes displayed in Figure 1.

Figure 1: Conceptual model

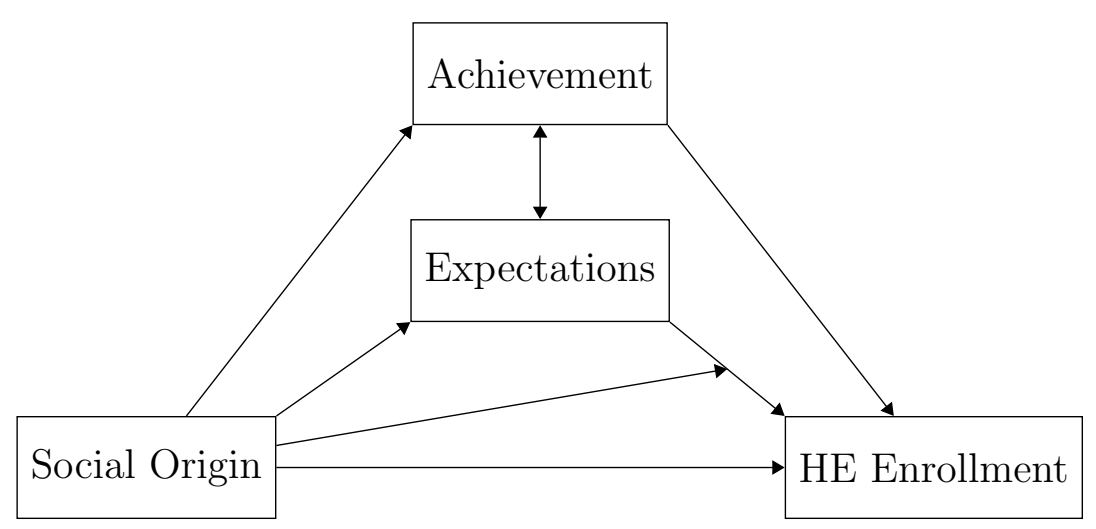


First, we look at the link between social origin and expectations. Second, we look at the translation of expectations into higher education enrollment for different SES groups. we focus on these relationships on top of achievement differences, asking the question whether social inequalities in expectations and higher education enrollment exist even when students show similar levels of achievement. Finally, we study how much of the relationship between social origin and higher education enrollment is explained by achievement and student expectations. Thereby, we determine how much of secondary effects of social origin can be explained by varying expectations across SES groups. These relationships are compared across two contexts with different educational systems: the United States and Germany.

We start with a description of the educational systems in the two countries that we study and their most salient features for the study of student expectations. Subsequently, we describe our theoretical framework for studying the development of expectations and the translation of expectations into higher education enrollment.

\section{The Context: Different Societies, Different Educational Systems}

Student expectations in the United States are inseparable from the American perspective on college education. Over the last decades an ethos of "college for all" has been promoted by policy makers and has largely been adopted by society at large (Rosenbaum, 2001; Baird et al., 2008). The goal is to make more students aim for a college education. This attitude towards college as norm shapes the context for students' educational expectations (Goyette, 2008). In Germany, the culture around expectations is very different. Traditionally, alternatives to college are highly valued and children are encouraged to find an educational pathway that suits their abilities and situation instead of aspiring to higher education at any cost.

The educational systems in the two countries reflect these general cultures around ambitions through various institutional features (Allmendinger, 1989). One institutional feature that differs strongly across the two countries is the level and type of ability tracking or streaming in secondary school. A simplified schematic overview of the two tracking systems can be found in Appendix A. Germany's educational system is characterized by strict 
separation in the form of between-school tracking while in the United States less strict course-by-course streaming prevails (Dupriez et al., 2008; Chmielewski, 2017). In Germany, the onset of between-school tracking happens early at the age of ten or twelve depending on the federal state. Students are allocated to different ability tracks in different schools at this age and follow their education separately from that point onwards. Some permeability between the tracks exists but in general upward transitions within secondary education are not very common (Jacob and Tieben, 2009). The highest track (Gymnasium) prepares students for studying at a university after obtaining an Abitur-diploma, the intermediate (Realschule) and lower tracks (Hauptschule) lead towards vocational training programs or vocational colleges. Some comprehensive schools (Gesamtschule) exist which offer all of those tracks under one roof, however, they play a rather minor role in the educational system. The educational system in the United States is less strictly differentiated than in Germany (Bol and Van de Werfhorst, 2013). Tracking mostly happens on a course-by-course basis and only starts at a later age. From seventh or eighth grade onwards, some ability streaming is in place at most schools. Grouping takes place within schools and it is possible to be placed in a high track in one subject but a lower track in another. Tracking is based on difficulty of courses (AP or honors versus regular classes) and on the timing of taking a course (e.g., taking a more advanced math or science course earlier in the school career). Students remain in the same school type until the end of secondary school.

A second difference between the two countries is the structure of the post-secondary educational system. Germany has a strongly developed vocational education and training sector. A substantial part of each student cohort enter apprenticeships or vocational schools after completing ninth or tenth grade in one of the lower tracks. These apprenticeships are well acknowledged on the labor market and provide students who do not enter higher education with a meaningful qualification. However, they also might divert low-SES students away from more prestigious higher education (Shavit and Müller, 2000, 1998). Higher education in Germany takes place at universities and vocational colleges (universities of applied sciences) which both grant Bachelor's and Master's degrees. Degrees at universities are in general academically oriented and most high prestige programs are offered at those institu- 
tions. Vocational colleges offer more applied programs (e.g., engineering, mid-level health care or social work programs). The vocational sector in the United States is much less developed (Bol and Van de Werfhorst, 2013). While a number of programs is offered, those are less widely recognized and serve more as a safety net for low achievers than providing decent prospects on the labor market (Arum and Shavit, 1995). Higher education in the US takes place at four-year colleges and research universities where Bachelor's and advanced degrees can be earned and at two-year colleges which offer associate degrees and short postsecondary certificates. There is a clear difference in prestige and labor market prospects in graduating from a four-year college and obtaining a degree at a two-year school.

Another salient difference between the two educational systems is the cost structure of higher education. The educational system of the US is characterized by high personal costs for higher education which vary across institutions and states. It is common for students to accumulate substantial amounts of debt for their studies. Although financial aid schemes are available, they are usually loan-based. Therefore, costs form a substantial financial or at least psychological barrier to college education especially for low-SES students (Grodsky and Jones, 2007). In Germany, higher education does not involve high direct costs. Most universities are public and only ask minor administrative fees. Additionally, there is a public loan and stipend system available to low income students.

Before looking more closely at student expectations and their variation across national contexts, it needs to be stated that we cannot disentangle the influence of different institutional features on expectations as we rely on a comparison of only two country cases. Nevertheless, the two countries that we study are chosen because of their quite different expectation cultures and educational systems which make them most dissimilar cases within the OECD. If there are differences in how expectations work as a mechanism of inequality, we are confident to find them in this set of countries. Furthermore, the outline of the different institutional features will help us to make predictions about differences across countries when it comes to the development and realization of student expectations. 


\section{The Development of Expectations}

First, we look at the link between social origin and expectations in Figure 1. We ask if the expectations that students develop are stratified by SES and if the level of stratification is different across the two educational systems that we study. Thereby, we are especially interested in whether such SES differences also exist if students show similar levels of academic achievement.

We focus on expectations in contrast to more idealistic aspirations in this paper. While educational aspirations are unconstrained wishes about one's future educational career, expectations take institutional barriers into account more strongly (Kerckhoff, 1976; Finger, 2016). As we are mostly interested in institutional variation and educational outcomes for different social groups, we focus on expectations.

Expectation development has been seen as a central part of status attainment and features prominently in the Wisconsin Status Attainment Model (Sewell et al., 1969; Sewell and Shah, 1968; Sewell et al., 2004; Andrew and Hauser, 2011). There, expectations are conceptualized as a function of socioeconomic group and ability. They develop through self-reflection about ability and through the influence of significant others' (parents, peers, and teachers). Students from lower socio-economic origin are confronted with lower expectations from their significant others concerning their educational development. Due to primary effects of social origin, they also show on average lower levels of early achievement, which reinforces low expectations.

Next to status attainment theory, expectations and beliefs about education are also assumed to be an important mechanism in rational choice models of educational attainment (Morgan, 1998, 2005; Breen, 1999). In these models, expectations are considered outcomes of rational calculations that take costs, benefits, and success probabilities for further education into account. Inequalities by SES, gender, and race are reproduced by rational choices that are based on social influences. Students from lower social origin or minority groups lower their expectations and their educational commitment according to the societal barriers that they face. 
On the one hand, these theories emphasize that expectations are stratified by SES as a result of differential achievement (primary effects). However, even at comparable levels of achievement, expectation differences across SES groups can be predicted. The socioeconomic environment of students not only affects their school achievement but it also creates financial barriers that enter cost-benefit calculations, it makes low-SES students more risk averse (Breen, 1999), and it influences their commitment to education (Morgan, 2005). Therefore, it can be assumed that secondary effects in expectation development exist.

Furthermore, levels of student expectations likely differ based on the national educational system. It has been hypothesized that tracking is a particularly important factor for the formation of expectations (Buchmann and Dalton, 2002; Buchmann and Park, 2009). In strictly tracked educational systems, such as the German one, students are strongly aware of their future opportunities as those are already limited by the track they are placed in early in their school career. They adjust their expectations according to these institutional realities (Karlson, 2015). In educational systems with less formal differentiation, like in the US, students are less aware of their opportunities. Barriers for future opportunities are more informal in the US and stem to a large extent from low school quality. However, information about the quality of their own school is less salient to students than an explicit track assignment. In addition, the college for all culture in the US encourages all students to develop high expectations which they keep until late in their educational trajectory (Reynolds et al., 2006; Goyette, 2008).

Buchmann and Dalton (2002) show that expectations indeed vary across educational systems with different levels of between-school tracking. They also show that in formally undifferentiated educational systems significant others play a major role for expectation formation while in differentiated systems, track placement strongly determines expectations. Chmielewski (2017) shows that average expectations are very low in systems with between-school tracking: students in the highest track in between-school tracking countries expect receiving about as much education as students in the lowest track in course-by-course tracking countries. 
Finally, strict tracking systems have been shown to be socially selective (Buchmann and Park, 2009; Parker et al., 2016). Low-SES students have a higher likelihood to be placed in lower tracks and track placement in turn affects expectations (Karlson, 2015). Therefore, especially low-SES students develop lower expectations early on, increasing the expectation gap between different social groups.

Following these theoretical considerations and previous research we make the following predictions for the level of expectations across SES groups and the two countries:

\section{H1(a): American students are more likely to hold high expectations than German students net of achievement.}

H1(b): High-SES students are more likely to hold high expectations than low-SES students net of achievement.

H1(c): The SES gap in expectations is larger in Germany than in the US net of achievement.

\section{The Realization of Expectations}

Next, we look at the link between expectations and educational outcomes. Here the question is how likely students are to realize their expectations. In other words, how strongly does having high expectations predict enrollment in higher education? We again look at socioeconomic differences and institutional influences net of achievement.

The link between expectations and outcomes has been mostly discussed under the term realism and has been defined in different ways in the literature. Kerckhoff (1977) sees realism in expectations as the relationship "between a group's average level of expected attainment and the experts' best estimates of predicted attainment" (p.566), using SES and ability as predictors. In this perspective, realism is a measure of whether a student's expectations match the social group the student belongs to with its specific graduation probabilities. Other studies have looked at whether the average expected educational attainment of students and the average actual attainment match each other on an aggregate 
level (e.g., Buchmann and Park, 2009; Jerrim, 2014). We diverge from these two definitions and employ a more direct measure of the link between expectations and attainment in different institutional settings. Instead of realism based on aggregate probabilities we study the actual realization of expectations on the individual level. We follow students throughout their educational career and look at how likely they are to enroll in higher education if they had college expectations in high school. Furthermore, we investigate if this predictive power of college expectations varies across socioeconomic groups and institutional contexts. In other words, do those students differ in their likelihood to realize their own expectations?

In the Wisconsin model, the link between expectations and attainment is portrayed as being very close. The realization of expectations is not a focus of the model but rather it is assumed that attainment directly follows from expectations. Some studies have even replaced a measure of educational attainment with a measure of expectations, arguing that expectations are a good proxy for educational attainment (Andrew and Flashman, 2017; Bozick et al., 2010; Roth, 2017). However, this automatism needs to be questioned. Especially with increasing educational expectations but stagnating higher education enrollment, the question needs to be asked whether students are able to realize high expectations or whether they likely will fall short of them (Reynolds et al., 2006; Baird et al., 2008; Rosenbaum, 2001). We do not question that expectations influence post-secondary enrollment and final educational attainment. This happens as expectations get translated to certain behavior that is or is not conducive for enrollment such as effort in high school, extracurricular activities, course taking, or college application behavior (Beal and Crockett, 2010; Domina et al., 2011). The main question in the present study is rather how strong this influence is.

Furthermore, the realization of expectations can increase social inequality if success rates differ across socioeconomic groups. Expectations of all SES groups have been on the rise in recent years but low-SES students still have lower levels of academic achievement than highSES students. Therefore, for them high expectations might be harder to realize. However, also on top of achievement differences, low-SES students face more barriers when it comes to the realization of their expectations as direct and indirect costs for higher education play 
a larger role for them. Furthermore, they might receive less encouragement and more mixed signals from their significant others in the transition to higher education (Morgan, 2005).

Hanson (1994) indeed finds that even if low-SES students have high expectations, they often fail to reach them. Furthermore, researchers have shown that a certain cooling-down process is happening to low-SES students. They often enroll in 2-year colleges with the hope of transferring to a 4-year school and obtaining a BA degree. During their time in junior college these hopes are often disappointed when students realize that they lack the background for successfully transferring to more prestigious colleges. (Clark, 1960; Alexander et al., 2008) Bozick et al. (2010) study in detail when in the school career expectations about higher education develop. They show that high-SES students often have more stable high expectations from an early age while low-SES students' expectations fluctuate more strongly even if they end up being high just before high school graduation. Stable expectations are connected to a higher probability of enrolling in higher education and to eventual graduation. Given this evidence, we expect that, in the United States, there are substantial differences across socioeconomic groups in how likely students are to realize high expectations.

So far, studies that follow students' realization of expectations on the individual level, have focused on the American context (Reynolds et al., 2006; Hanson, 1994). We add a comparative element to the longitudinal study of the link between student expectations and outcomes by comparing two countries with very different educational systems. In contrast to the US, we hypothesize for Germany that expectations are overall lower and more realistic. Expectations in Germany are strongly determined by track placement. Students adapt their expectations to the opportunities that are available to them earlier in the school career (Buchmann and Park, 2009). They are subsequently also more likely to follow up on those expectations. Relatedly, it can be expected that SES differences in realization are less stark in Germany than in the US where low-SES students hold much higher hopes for their education. As track placement is socially selective, low-SES students develop lower - and more realistic - expectations earlier on, so that we can expect to see smaller social differences in realization of expectations. Furthermore, in the US informal barriers such as 
costs or differences in high school quality are more prominent, hindering low-SES students' enrollment.

Empirical research shows the institutional variations in realism of expectations at a cross-sectional level. Buchmann and Park (2009) compare student expectations at age 15 in five countries with between-school tracking to five countries with formally undifferentiated educational systems. They show that in tracked systems the share of students who expect to complete higher education corresponds closely to the actual share of higher education graduates while students have unrealistically high expectations in less differentiated countries. Also Jerrim (2014) and Reynolds et al. (2006) confirm this relationship comparing population level averages of college expectations and enrollment rates. However, no comparative longitudinal assessment of the realization of expectations has been conducted to date. Overall, we make the following predictions concerning the realization of expectations:

H2(a): Students in Germany have a higher likelihood to realize high expectations than students in the US net of achievement.

H2(b): High-SES students have a higher likelihood to realize high expectations than lowSES students net of achievement.

H2(c): The SES differences in realization are more pronounced in the US than in Germany net of achievement.

\section{Decomposition of the Social Origin Effect}

Finally, we look at the entire process of the development of social inequality in educational attainment. We are interested in whether expectations can explain part of the social origin effect on higher education enrollment.

To investigate how much of the SES differences are mediated by student expectations, we decompose the effect of social origin on higher education enrollment into a part that operates via achievement differences (primary effects), a part that runs through expectations (on top of primary effects), and a residual direct effect that cannot be explained by neither achievement nor expectations. 
We expect that primary effects of social origin compared to secondary effects are stronger in Germany than in the US due to the strong ability sorting in the tracked educational system. As a consequence, the total remaining secondary effect will be smaller in Germany. Furthermore, we hypothesized above that, net of achievement, expectations are more strongly stratified by SES and also a stronger predictor of higher education enrollment in Germany than in the US. Therefore, we hypothesize that expectations explain a larger part of these remaining secondary effects in Germany.

H3(a): The share of primary effects in the total SES effect is larger in Germany than in the US.

H3(b): Expectations explain a larger part of the remaining secondary effects in Germany than in the US.

\section{Data and Methods}

\section{Data and Sample}

The data for our empirical investigation come from two longitudinal cohort studies. For Germany, we use the National Educational Panel Study (NEPS, Starting Cohort 4, data version 9.1.1) (Blossfeld and von Maurice, 2011). For the US, we rely on data from the High School Longitudinal Study (HSLS) (US Department of Education, 2009).

Table 1 shows information on the student samples in the two data sets. We use data for age 15 to $20 / 21$ from both data sets to obtain comparable measures for both countries. About 95 percent of HSLS student were born in 1994 and 1995. Around 90 percent of NEPS students were born in the years 1995 and 1996 and another 9 percent in 1994. Therefore, the two samples are highly comparable in ages and cohorts covered.

In both surveys, we are confronted with missing data which especially in the NEPS sample seem to be selective. Students from low socioeconomic background and lower track placement answered questions about their expectations less often. We address this problem 
Table 1: Data Sets for the two Countries

\begin{tabular}{lll}
\hline & United States & Germany \\
\hline Data set & HSLS 2009 & NEPS SC4 \\
Birth years students & $1994 / 95$ & $1995 / 96$ \\
Ages at which surveyed & $15,17,18,21$ & $15,16,17,18,19,20$ \\
Sample size wave 1 & 23,503 & 16,425 \\
Sample used & 17,201 & 9,044 \\
\hline
\end{tabular}

by using multiple imputation for all independent variables. ${ }^{1}$ This leads to a sample of 9,044 students for the NEPS and 17,021 students for the HSLS for which information on higher education enrollment is available.

\section{Operationalization}

Table 2 shows all variables that we use, how they are measured in the two data sets, as well as means or shares for each category of each variable for the imputed sample. ${ }^{2}$

Our main interest is in the educational expectations of students. In both surveys expectations were assessed by asking students about their plans for education after secondary school. Due to the differences in the educational systems, the question text varied slightly. In the HSLS students were asked: "How far in school do you expect to go?". School refers to all types of education in this case. Students were asked this question at age 15, 17, and 21. In the NEPS the question was: "Considering all you know now, what kind of training do you expect to do after school?" School refers to the current secondary school of a student in this context. The question was administered to students at age 17, 18, 19, and 20.

To make expectations comparable across countries, we look at a dichotomized version of expectations. This simplification is justified as we are mostly interested in whether high expectations get realized. We define high expectations as the expectation to complete a university or four-year college degree in both countries. Expectations are considered as low if the student expects enrollment at a second-tier institution (two-year college/university of

\footnotetext{
${ }^{1}$ We use 20 imputed datasets and also include the dependent variable (enrollment) in our imputation model. However, we do not use imputed cases of enrollment in our analysis (imputation then deletion approach (Von Hippel, 2007)). More information on the imputation model can be found in Appendix B.

${ }^{2}$ We do not show standard deviations as it is debated how meaningful they are with multiple imputation data.
} 
Table 2: Coding of Variables and Descriptive Statistics for the Two Datasets

\begin{tabular}{|c|c|c|c|c|}
\hline VARIABLES & Measurement HSLS & MEAN & MEASUREMENT NEPS & MEAN \\
\hline High Expectations & At age 17 & & At age 17 & \\
\hline No & $\begin{array}{l}\text { HS degree or less, Some col- } \\
\text { lege, Assoc. Degree }\end{array}$ & 0.29 & $\begin{array}{l}\text { No Higher Education, Univ. of } \\
\text { Appl. Sciences }\end{array}$ & 0.63 \\
\hline Yes & BA degree or more & 0.71 & University & 0.37 \\
\hline Higher Education Enrollment & At age 21 & & At age 20 & \\
\hline Not high & $\begin{array}{l}\text { Not enrolled, Certificate, As- } \\
\text { soc. Degree }\end{array}$ & 0.59 & $\begin{array}{l}\text { Not enrolled, Univ. of Appl. } \\
\text { Sciences }\end{array}$ & 0.79 \\
\hline High & BA degree or more & 0.41 & University & 0.21 \\
\hline \multicolumn{5}{|l|}{ SES (Parents' education) } \\
\hline Low & HS degree or less & 0.41 & Intermediate Secondary or less & 0.52 \\
\hline Intermediate & Some college/Assoc. Degree & 0.15 & (Fach-)Abitur & 0.21 \\
\hline High & BA degree or more & 0.44 & Higher education & 0.27 \\
\hline Mathematics Competence & At age 15 & 0.08 & At age 15 & 0.16 \\
\hline Female & & 0.51 & & 0.50 \\
\hline \multicolumn{5}{|l|}{ Race/Ethnicity } \\
\hline & Asian & 0.08 & & \\
\hline & Black & 0.10 & & \\
\hline & Hispanic & 0.16 & & \\
\hline & White & 0.56 & & \\
\hline & Other & 0.10 & & \\
\hline Migration Background & & & Parent born Abroad & 0.23 \\
\hline $\mathrm{N}$ & & 17,201 & & 9,044 \\
\hline
\end{tabular}


applied sciences) or no higher education enrollment at all. We use the measure of expectations when students are 17 years old as this is the earliest measurement point available for the United States.

Our outcome is enrollment in higher education when the student is 20 or 21 years old. Also this measure is dichotomized to make it comparable to the measure of expectations and across countries. A student is considered as having a high enrollment if they are enrolled at university or a four-year college. Enrollment is considered to be low if students are not enrolled in higher education or attend a second-tier institution. ${ }^{3}$

Students' social origin is measured using parents' education. To make SES groups comparable, we look at comparably sized categories across countries as far as possible and create three categories of parental SES, low, intermediate and high. The low-SES category contains those with high school degree or less in the US and those with an intermediate secondary school degree (Mittlere Reife) or less in Germany. The intermediate-SES group contains those with some college education or an associate degree in the US and those with Abitur (the highest secondary school degree) in Germany. Finally, in the US parents with a Bachelor's degree or more are considered as high-SES while all parents with a higher education degree are in this category in Germany. These categories are somewhat different from the enrollment categories that we use for students. This has two reasons. First, it is not possible to distinguish different higher education degrees for parents in the German data. Second, degrees in higher education have a different meaning in the parent generation anyway and the comparison between Germany and the US might be different for this generation than for the students themselves. We, therefore, focus on creating parental SES groups that are comparable in size across the two countries in order to equate similar parts of the societal SES distribution.

Furthermore, we use mathematics competence as a proxy for academic achievement in both countries. Mathematics achievement is suitable to this end as it is a central subject

\footnotetext{
${ }^{3}$ We would prefer to assess final educational attainment of students as the question on expectations refers to educational degrees but neither of the data sets covers students beyond the age of 21 to this date. Instead we study in which type of post-secondary institution students are enrolled or, in some cases, which degree they have already completed. We use this measure as a way of assessing if students are on the right path to eventually realizing their expectations.
} 
in the curriculum and highly consequential for further educational opportunities. In both data sets, a mathematics test was carried out in the first wave at age 15. The test scores are standardized within countries to have a mean of zero and a standard deviation of one. A complication of the associations that we are studying is that the relationship between expectations and achievement is likely reciprocal. Achievement influences expectations and those in turn affect subsequent achievement. We cannot fully capture those reciprocal processes in this paper. Conditioning on achievement that is measured before expectations are measured, however, is at least a way to account for the effect of previous achievement on expectations and thereby the mediating role achievement plays in explaining SES effects. ${ }^{4}$

Finally, we control for gender as well as for a measure of race and ethnicity in the United States and an indicator of migration background in Germany. We are interested in SES effects on expectations and enrollment, and want to look at those net of these other demographic characteristics.

\section{Empirical Strategy}

To investigate $\mathrm{H} 1(\mathrm{a}), \mathrm{H} 1(\mathrm{~b})$, and $\mathrm{H} 1(\mathrm{c})$, we employ linear probability models that predict the likelihood of "having high expectations" from students' SES while controlling for achievement, gender, as well as race and migration background. We use linear probability models to predict this dichotomous outcome as their interpretation is more accessible than that of logistic regression models. ${ }^{5}$ All models are estimated using robust standard errors. The results are reported in Table 3 and Figure 2.

To investigate $\mathrm{H} 2(\mathrm{a}), \mathrm{H} 2(\mathrm{~b})$, and $\mathrm{H} 2(\mathrm{c})$, we again estimate linear probability models to predict university/four-year-college enrollment and how strongly high expectations at age 17 are related to it net of achievement and demographic characteristics. In a second step, we add an interaction between social origin and expectations to study social differentials in the realization of expectations. The results are displayed in Table 4 and Figure 3.

\footnotetext{
${ }^{4}$ In the analysis with expectations as outcome, accounting for previous achievement instead of current achievement also avoids that achievement acts as a collider in the model. Nevertheless, the processes that we are modeling cannot be interpreted in a causal way.

${ }^{5} \mathrm{~A}$ robustness check using logistic regression leads to very similar results.
} 
Finally, to assess H3(a) and H3(b), we look at an analysis that decomposes the total effect of social origin on attainment into achievement related differences (primary effects), differences explained by expectations once it is accounted for achievement, and a residual effect that signals the part of secondary effects that cannot be explained by expectation differences. Results can be seen in Table 5 and Figure 4.

\section{Results}

We discuss the results in three steps: First, we focus on the association between SES and levels of expectations across countries. Subsequently, we investigate the realization of high expectations across countries and for different SES groups. Finally, we decompose the social origin effect on university enrollment to show how much of it is mediated by achievement and expectations.

\section{Level of Expectations}

Table 2 above shows that in the US, 71 percent of students in the imputed sample have high expectations at age 17 which means that they expect to obtain a Bachelor's degree or more. In Germany only 37 percent have high expectations and expect to go to University. Overall, the level of expectations is, therefore, much lower in Germany than in the US. In the US, a large majority of students expect to reach degrees from first-tier higher education institutions, while in Germany a majority of students does not expect to go to university. This finding also holds when controlling for achievement and demographic characteristics such as in Table 3; the overall predicted probability of having high expectations for the US is still 0.71 and for Germany it is still 0.37. This is consistent with H1(a).

Next to the overall level of expectations in the two countries net of achievement, we are interested in how SES is related to expectations. In Table 3 all coefficients for SES are significant. For high-SES, we find a positive effect: the predicted probability of having high expectations is 19 percentage points higher for high-SES students than for low-SES students in the United States and 5 percentage points higher in Germany net of achievement 
Table 3: Linear Probability Models Predicting High Educational Expectations

\begin{tabular}{|c|c|c|}
\hline & United States & Germany \\
\hline \multicolumn{3}{|c|}{ Parents' Education $($ Ref $=$ Low $)$} \\
\hline Intermediate & $\begin{array}{r}-0.03^{*} \\
(0.01)\end{array}$ & $\begin{array}{c}-0.07^{* * *} \\
(0.02)\end{array}$ \\
\hline High & $\begin{array}{l}0.19^{* * *} \\
(0.01)\end{array}$ & $\begin{array}{l}0.05^{* *} \\
(0.02)\end{array}$ \\
\hline Math Score & $\begin{array}{l}0.13^{* * *} \\
(0.00)\end{array}$ & $\begin{array}{l}0.12^{* * *} \\
(0.00)\end{array}$ \\
\hline Female & $\begin{array}{l}0.08^{* * *} \\
(0.01)\end{array}$ & $\begin{array}{l}0.12^{* * *} \\
(0.01)\end{array}$ \\
\hline \multicolumn{3}{|c|}{ Race/Ethnicity (Ref = White) } \\
\hline Asian & $\begin{array}{c}0.01 \\
(0.01)\end{array}$ & \\
\hline Black & $\begin{array}{l}0.08^{* * *} \\
(0.01)\end{array}$ & \\
\hline Hispanic & $\begin{array}{r}-0.01 \\
(0.01)\end{array}$ & \\
\hline Other & $\begin{array}{c}0.01 \\
(0.01)\end{array}$ & \\
\hline Parent Born Abroad & & $\begin{array}{c}0.01 \\
(0.02)\end{array}$ \\
\hline Constant & $\begin{array}{l}0.57^{* * *} \\
(0.01)\end{array}$ & $\begin{array}{l}0.29^{* * *} \\
(0.03)\end{array}$ \\
\hline $\mathrm{R}$ squared & 0.18 & 0.11 \\
\hline Observations & 17,201 & 9,044 \\
\hline
\end{tabular}

B-coefficients, standard errors in parentheses.

Significance: ${ }^{*} p<0.05,{ }^{* *} p<0.01,{ }^{* * *} p<0.001$

Source: HSLS 2009 and NEPS SC4. Own Calculations. 
and the other controls. This confirms H1(b). The difference between low and intermediate SES is significant but the relationship is negative in both countries. Having parents with intermediate education leads on average to somewhat lower expectations than having parents with low education net of achievement. This is not in line with $\mathrm{H} 1(\mathrm{~b})$. There are several reasons for those seemingly odd results for the middle group. One needs to keep in mind that these are secondary effects and students are compared within achievement groups. Given similar achievement, students of intermediate SES are less positive about their prospects than low-SES students. This might be the case if they compare themselves to peers of similar SES. Low-SES students might compare more favorable in the comparison to their low-SES peers while intermediate-SES students with the same performance level might fall short compared to their peers. ${ }^{6}$ Another reason could be that low-SES students are less aware of barriers in the educational system than intermediate-SES students and therefore stay more optimistic.

To investigate SES differences, also across countries, more in detail, Figure 2 shows the predicted probabilities of having high expectations for the three SES groups.

For all three SES groups, student expectations are much lower in Germany than they are in the US. While all groups in the US have a probability of above 0.6 to have high expectations, the probability does not get much higher than 0.4 in Germany consistent with H1(a). For the US low- and intermediate-SES students have very similar probabilities of having high expectations. Low-SES students have a probability of 0.63 of having high expectations, intermediate-SES student a probability of 0.61 and for high-SES students the probability is 0.82 , leaving a gap of 19 percentage points between the lowest and highest SES group. In Germany, there is a smaller absolute gap between the SES groups, particularly between students with low SES on the one hand and high SES on the other. Low-SES students' probability for high expectations is 0.37 , while it is 0.42 for high-SES students - a gap of only 5 percentage points. Also when we look at relative differences instead of absolute, the conclusions remain the same. Compared to high-SES students, expectations of low-SES students are 12 percent lower in Germany. The same difference is 23 percent in

\footnotetext{
${ }^{6}$ This explanation is supported by the analyses in Appendix $\mathrm{C}$ which shows the results without controlling for achievement.
} 
Figure 2: Predicted Probability of Having High Expectations by SES

(a) United States

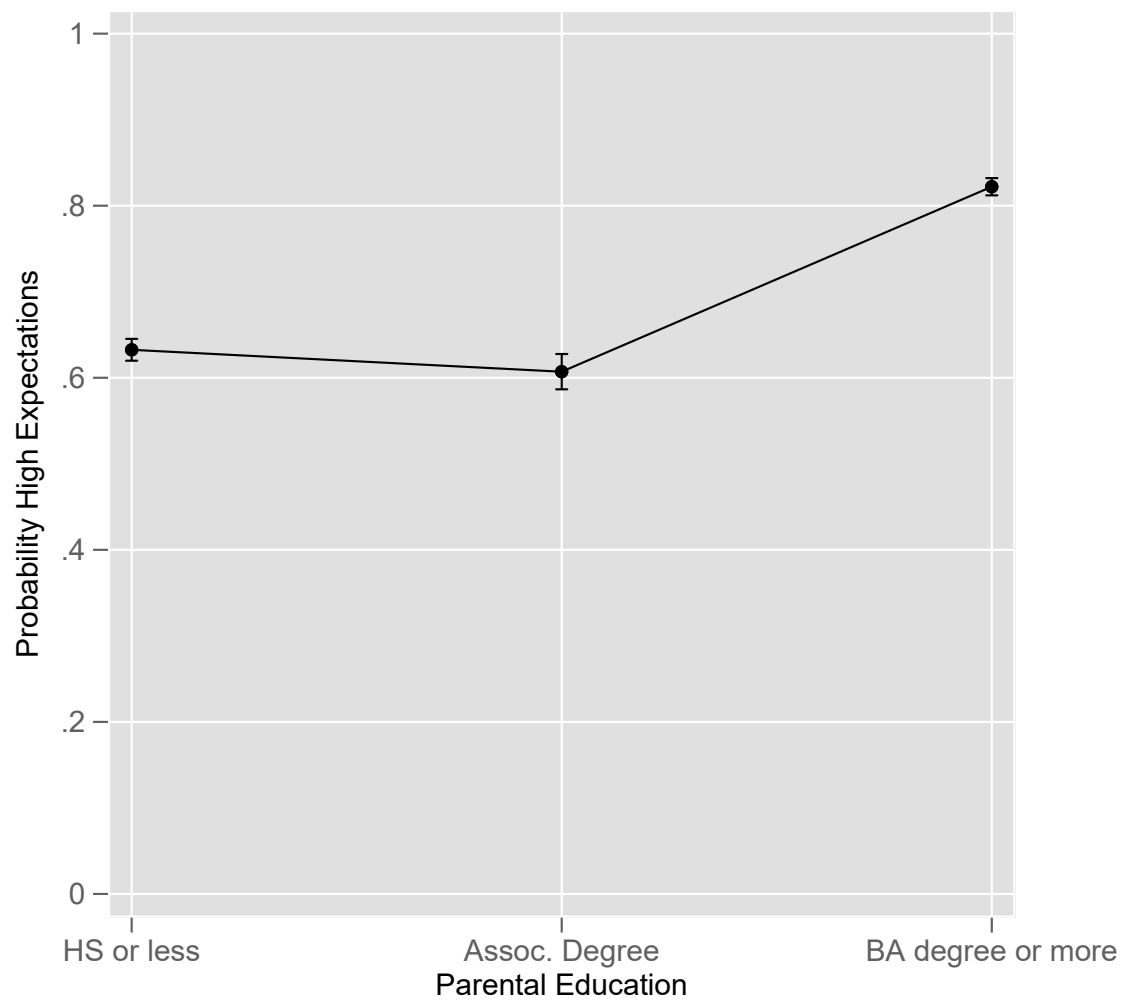

(b) Germany

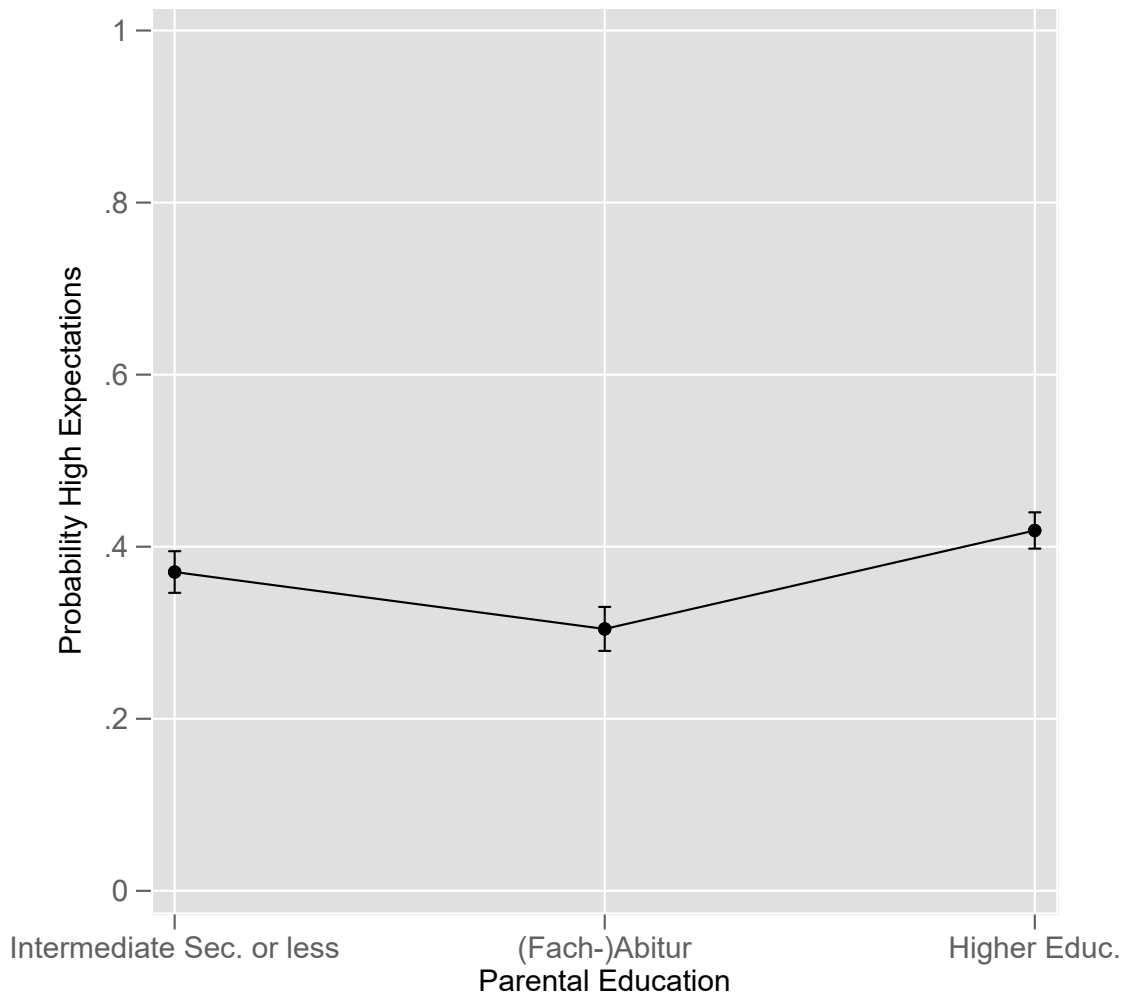

Predicted Probabilities based on models in Table 3.

Source: HSLS 2009 and NEPS SC4. Own Calculations. 
the US. The SES gap in expectations in Germany is smaller than in the United States contrary to $\mathrm{H} 1(\mathrm{c})$.

\section{Realization of Expectations}

Next, we look at the second part of the indirect relationship between social origin and enrollment that runs through expectations: the link between expectations and higher education enrollment, thereby assessing $\mathrm{H} 2(\mathrm{a}), \mathrm{H} 2(\mathrm{~b})$, and $\mathrm{H} 2(\mathrm{c})$ about the realization of expectations. Table 4 shows the results from linear probability models predicting university/fouryear-college enrollment. With these models, we assess whether students are likely to realize their high expectations by translating them into university enrollment. All models control for mathematics performance and the demographic control variables to estimate an SES effect net of these factors.

Model 1 shows that having high expectations increases the probability to enroll in university net of parental SES, achievement and the other control variables. The strength of this relationship is very comparable across the two countries. In the US having high expectations increases the probability to enroll at university by 24 percentage points, in Germany the increase is 23 percentage points. This difference is negligible and so, in any case, we cannot confirm H2(a): students in Germany are not more likely to realize high expectations.

We also see a positive effect of parental SES. In the US, high-SES students are 25 percentage points more likely to enroll in university net of expectations, achievement, and the other controls. In Germany, this difference between low- and high-SES students is 17 percentage points. The persisting effect of parental SES in this case also shows that part of secondary effects remain unexplained after accounting for the influence of expectations. We investigate this more in detail below.

Model 2 looks at SES differences in how likely expectations get realized by introducing an interaction effect between SES and having high expectations. All interaction terms are positive and significant. Net of achievement and the other control variables, for higher SES students, the relationship between having high expectations and enrolling in university is 
Table 4: Linear Probability Models Predicting University Enrollment by Parental SES and Expectations

\begin{tabular}{|c|c|c|c|c|}
\hline & \multicolumn{2}{|c|}{ United States } & \multicolumn{2}{|c|}{ Germany } \\
\hline & (1) & $(2)$ & (1) & $(2)$ \\
\hline High Expectations (ref=Low) & $\begin{array}{l}0.24^{* * *} \\
(0.01)\end{array}$ & $\begin{array}{l}0.18^{* * *} \\
(0.01)\end{array}$ & $\begin{array}{l}0.23^{* * *} \\
(0.01)\end{array}$ & $\begin{array}{l}0.16^{* * *} \\
(0.01)\end{array}$ \\
\hline \multicolumn{5}{|l|}{ Parents' SES (ref=Low) } \\
\hline Intermediate & $\begin{array}{l}0.07^{* * *} \\
(0.01)\end{array}$ & $\begin{array}{c}0.03^{*} \\
(0.01)\end{array}$ & $\begin{array}{l}0.09^{* * *} \\
(0.01)\end{array}$ & $\begin{array}{l}0.04^{* * *} \\
(0.01)\end{array}$ \\
\hline High & $\begin{array}{l}0.25^{* * *} \\
(0.01)\end{array}$ & $\begin{array}{l}0.11^{* * *} \\
(0.02)\end{array}$ & $\begin{array}{l}0.17^{* * *} \\
(0.01)\end{array}$ & $\begin{array}{l}0.10^{* * *} \\
(0.01)\end{array}$ \\
\hline \multicolumn{5}{|c|}{ High Expectations $\times$ Parents' SES $($ ref $=$ Low $)$} \\
\hline$\times$ Intermediate SES & & $\begin{array}{l}0.07^{* * *} \\
(0.02)\end{array}$ & & $\begin{array}{l}0.14^{* * *} \\
(0.03)\end{array}$ \\
\hline$\times$ High SES & & $\begin{array}{l}0.19^{* * *} \\
(0.02)\end{array}$ & & $\begin{array}{l}0.17^{* * *} \\
(0.02)\end{array}$ \\
\hline Math Score Age 15 & $\begin{array}{l}0.13^{* * *} \\
(0.00)\end{array}$ & $\begin{array}{l}0.13^{* * *} \\
(0.00)\end{array}$ & $\begin{array}{l}0.09^{* * *} \\
(0.00)\end{array}$ & $\begin{array}{l}0.08^{* * *} \\
(0.00)\end{array}$ \\
\hline Female & $\begin{array}{l}0.07^{* * *} \\
(0.01)\end{array}$ & $\begin{array}{l}0.07^{* * *} \\
(0.01)\end{array}$ & $\begin{array}{l}0.06^{* * *} \\
(0.01)\end{array}$ & $\begin{array}{l}0.06^{* * *} \\
(0.01)\end{array}$ \\
\hline \multicolumn{5}{|l|}{ Race/Ethnicity (Ref $=$ White $)$} \\
\hline Asian & $\begin{array}{l}0.05^{* * *} \\
(0.01)\end{array}$ & $\begin{array}{l}0.05^{* * *} \\
(0.01)\end{array}$ & & \\
\hline Black & $\begin{array}{c}-0.02 \\
(0.01)\end{array}$ & $\begin{array}{c}-0.02 \\
(0.01)\end{array}$ & & \\
\hline Hispanic & $\begin{array}{c}-0.03^{* * *} \\
(0.01)\end{array}$ & $\begin{array}{c}-0.03^{* * *} \\
(0.01)\end{array}$ & & \\
\hline Other & $\begin{array}{c}-0.05^{* * *} \\
(0.01)\end{array}$ & $\begin{array}{c}-0.04^{* * *} \\
(0.01)\end{array}$ & & \\
\hline Parent Born Abroad & & & $\begin{array}{l}0.04^{* * *} \\
(0.01)\end{array}$ & $\begin{array}{l}0.04^{* * *} \\
(0.01)\end{array}$ \\
\hline Constant & $\begin{array}{l}0.08^{* * *} \\
(0.01)\end{array}$ & $\begin{array}{l}0.12^{* * *} \\
(0.01)\end{array}$ & $\begin{array}{c}0.01 \\
(0.01)\end{array}$ & $\begin{array}{l}0.03^{* * *} \\
(0.01)\end{array}$ \\
\hline $\mathrm{R}$ squared & 0.31 & 0.32 & 0.26 & 0.27 \\
\hline Observations & 17,201 & 17,201 & 9,044 & 9,044 \\
\hline
\end{tabular}

B-coefficients, standard errors in parentheses.

Significance: ${ }^{*} p<0.05,{ }^{* *} p<0.01,{ }^{* * *} p<0.001$

Source: HSLS 2009 and NEPS SC4. Own Calculations. 
stronger than for low-SES students. They have a higher probability to realize their high expectations. For the US, high-SES students with high expectations are 19 percentage points more likely to enroll in university than low-SES students with high expectations net of achievement and other controls. For Germany, this difference is 17 percentage points. This confirms $\mathrm{H} 2(\mathrm{~b})$.

Figure 3 shows the size of these SES differences across the two countries more clearly using predicted probabilities for the different SES groups and different levels of expectations.

The blue line shows the predicted probability to enroll in university for all students that had high expectations at age 17. Overall, the levels of realization are comparably high for the US and Germany. As already seen in Table 4, both countries show significant SES differences in how likely those students are to realize their expectations. Low-SES students (left side of x-axis) with high expectations are more likely to fall short of their expectations than high-SES students (right side of the x-axis).

In the US, the enrollment probability for low-SES students with high expectations (keeping everything else constant) is about 0.34 , for high-SES students this enrollment probability is 0.63, a gap in enrollment probability of 29 percentage points. For Germany, low-SES students with high expectations have a probability of 0.24 , high-SES students of 0.51 . Here the gap is 26 percentage points. Looking at relative differences we find similar results. High-SES students with high expectations in the US are 1.49 times more likely to enroll at a university than low-SES students. In Germany high-SES students are 1.53 times more likely to enroll. The absolute SES difference is slightly larger in the US but the relative difference is somewhat larger in Germany. Therefore, H2(c) is not confirmed. The country differences in SES gaps are negligible and not clearly pointing in one direction.

Overall, it can also be seen that in both countries a substantial share of students falls short of their high expectations. Even high-SES students with high expectations have only a predicted probability of enrolling in university of 63 percent in the US and 51 percent in Germany net of achievement, and other socio-demographic characteristics. A substantial share of students do not realize their expectations in both countries. Nevertheless, having high expectations increases - all else equal — the likelihood of going to college. This can 
Figure 3: Predicted Probability of University Enrollment by SES and Level of Expectations

(a) United States

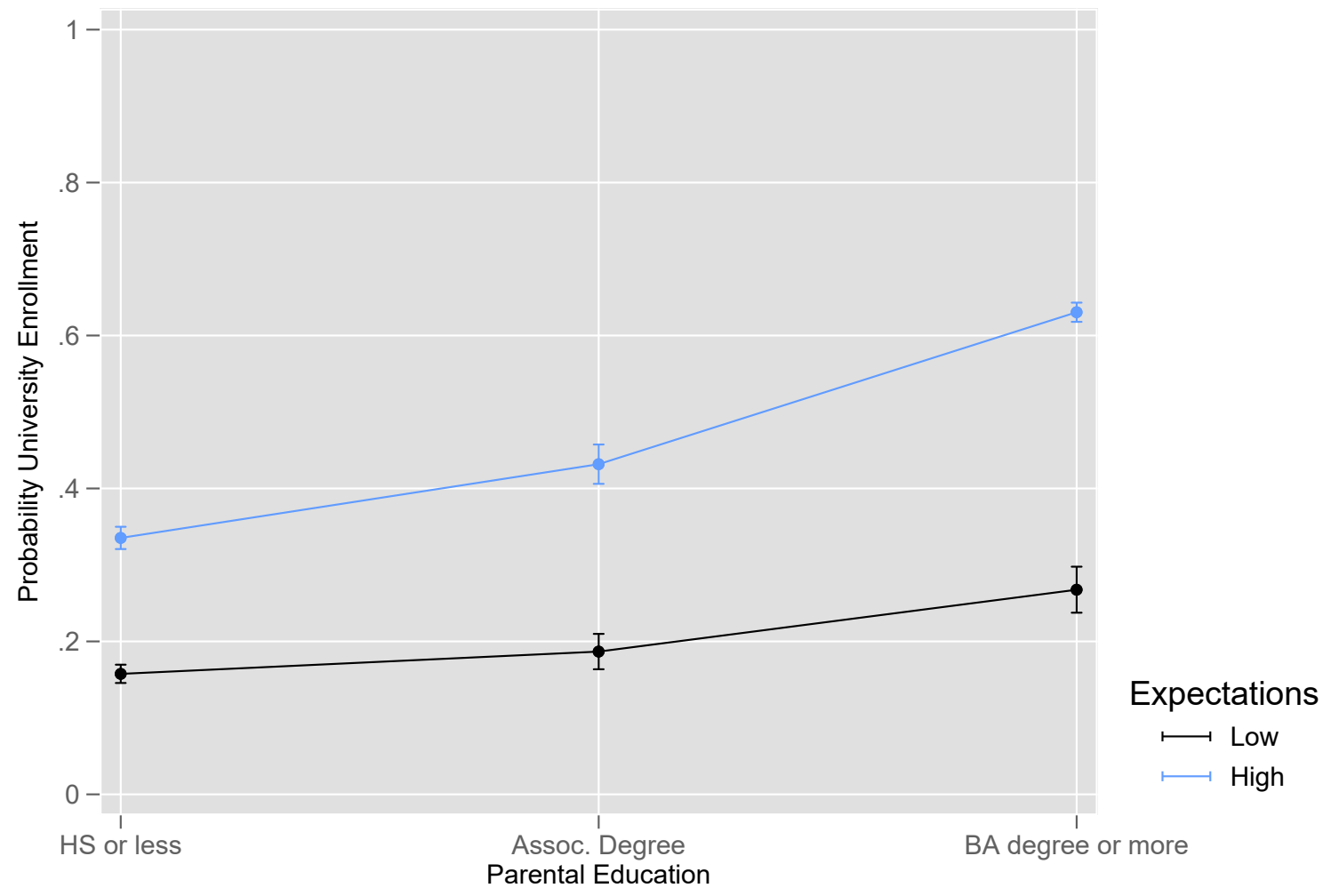

(b) Germany

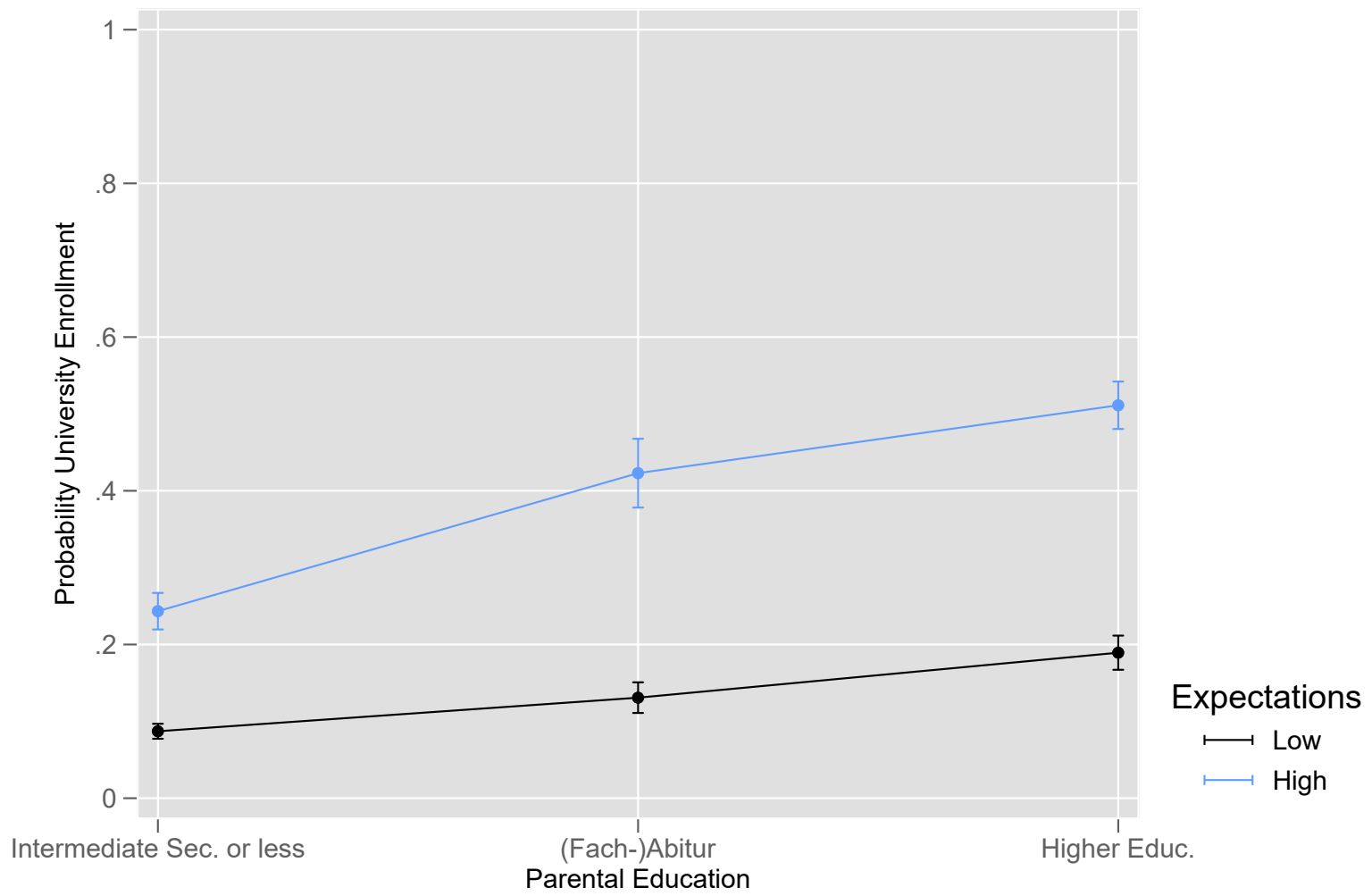

Predicted Probabilities based on Model 2 in Table 4.

Source: HSLS 2009 and NEPS SC4. Own Calculations. 
also be seen by the clear difference between students with high expectations (blue line) and low expectations (black line) in Figure 3.

\section{A Note on the Role of Achievement}

All reported models control for achievement as we are, in particular, interested in the effects of expectations on top of achievement differences. The role of expectations might look differently though if we do not adjust for achievement differences. Appendix $\mathrm{C}$ shows all results without any controls for achievement.

The overall conclusion from these additional models is that our results hold up to this alternative specification. When we do not only look at secondary effects but also let achievement differences influence expectations, we still find similar SES effects across the two countries. In particular, the overall level of expectations is still higher in the US than in Germany, confirming H1(a). Also higher SES students still show higher expectations than low-SES students, confirming H1(b). The total gap between high and low-SES students is larger in models without achievement controls as it also picks up achievement related differences in expectations and not only those on top of achievement. Also the comparison across countries remains similar with the US showing a larger SES gap than Germany. H1(c) is still not confirmed.

For the realization of expectations, the conclusions also remain basically the same. The level of realization is very similar in the two countries (0.31 in the US, 0.29 in Germany). High-SES students have a higher probability to realize their expectations than low-SES students and these SES differences are similar across the two countries. Therefore, H2(a) and $\mathrm{H} 2(\mathrm{c})$ are not confirmed while $\mathrm{H} 2(\mathrm{~b})$ is confirmed.

Controlling for achievement and only looking at secondary effect does not drive our results. The same conclusions can be drawn when we let expectations also pick up primary effects of social origin. 
Table 5: Decomposition of the Total SES Effect - Reduction of Coefficients

\begin{tabular}{|c|c|c|c|c|c|c|}
\hline & \multicolumn{3}{|c|}{ United States } & \multicolumn{3}{|c|}{ Germany } \\
\hline & $(1)$ & $(2)$ & (3) & $(1)$ & $(2)$ & (3) \\
\hline \multicolumn{7}{|l|}{ Parents' SES (ref=Low) } \\
\hline \multirow[t]{2}{*}{ Intermediate } & $0.09^{* * *}$ & $0.06^{* * *}$ & $0.07^{* * *}$ & $0.13^{* * *}$ & $0.07^{* * *}$ & $0.09^{* * *}$ \\
\hline & $(0.01)$ & $(0.01)$ & $(0.01)$ & $(0.01)$ & $(0.01)$ & $(0.01)$ \\
\hline \multirow[t]{2}{*}{ High } & $0.41^{* * *}$ & $0.30^{* * *}$ & $0.25^{* * *}$ & $0.28^{* * *}$ & $0.18^{* * *}$ & $0.17^{* * *}$ \\
\hline & $(0.01)$ & $(0.01)$ & $(0.01)$ & $(0.01)$ & $(0.01)$ & $(0.01)$ \\
\hline \multirow[t]{2}{*}{ Math Score Age 15} & & $0.16^{* * *}$ & $0.13^{* * *}$ & & $0.12^{* * *}$ & $0.09^{* * *}$ \\
\hline & & $(0.00)$ & $(0.00)$ & & $(0.00)$ & $(0.00)$ \\
\hline \multirow[t]{2}{*}{ High Expectations (ref=Low) } & & & $0.24^{* * *}$ & & & $0.23^{* * *}$ \\
\hline & & & $(0.01)$ & & & $(0.01)$ \\
\hline \multirow[t]{2}{*}{ Constant } & $0.19^{* * *}$ & $0.22^{* * *}$ & $0.08^{* * *}$ & $0.09^{* * *}$ & $0.07^{* * *}$ & 0.01 \\
\hline & $(0.01)$ & $(0.01)$ & $(0.01)$ & $(0.01)$ & $(0.01)$ & $(0.01)$ \\
\hline $\mathrm{R}$ squared & 0.19 & 0.27 & 0.31 & 0.09 & 0.20 & 0.26 \\
\hline Observations & 17,201 & 17,201 & 17,201 & 9,044 & 9,044 & 9,044 \\
\hline
\end{tabular}

Models also control for gender and race/migration background.

Standard errors in parentheses.

Significance: ${ }^{*} p<0.05,{ }^{* *} p<0.01,{ }^{* * *} p<0.001$

Source: HSLS 2009 and NEPS SC4. Own Calculations.

\section{Decomposition of the Social Origin Effect}

Finally, we turn to the decomposition of SES effects. We are interested in the role that expectations play in explaining effects of social origin on students' university enrollment. Table 5 and Figure 4 show the decomposition of the total effect of social origin (net of gender and race/migration) into different components. we investigate how much of the SES effect can be explained by achievement differences (primary effect), how much of the remaining secondary effects can be explained by differences in expectations and, finally, how much is unexplained residual inequality even when expectations are accounted for.

In Table 5, Model 1 shows the total SES effect net of other demographic characteristics (gender and race/migration). If we look at the difference between low and high SES, we see that the overall SES effect is larger for the US than for Germany: being high SES instead of low-SES increases the probability to enroll in university by 0.41 in the US and 0.28 in Germany. Model 2 shows the decrease of the SES effect after accounting for achievement. The effect for high versus low-SES significantly decreases by 0.11 in the US and 0.10 in 
Germany when it is accounted for achievement. ${ }^{7}$ Achievement, therefore, mediates the social origin effect. The absolute reduction of the effect of social origin is almost equally large in the two countries. The remaining SES effect is 0.30 in the US and 0.18 in Germany. In the US students with high instead of low SES have on average a 0.3 higher probability of enrolling in university even when they perform at similar levels. In Germany this difference is 0.18 . This is the total secondary effect of social origin. Finally, in Model 3 expectations are added. The SES effect decreases by 0.05 in the US and 0.01 in Germany after accounting for expectations. For Germany, however, this mediation effect is not significant. The residual SES effect that cannot be explained by achievement or expectations is 0.25 in the US and 0.17 in Germany. High-SES students are still more likely to enroll in university than lowSES students even with similar levels of achievement and expectations. This is the residual secondary effect that does not run through expectations.

The story is less clear if we look at differences between low- and intermediate-SES students. For them achievement does mediate part of the SES effect but accounting for expectations does slightly increase the differences between low- and intermediate-SES students. This is similar to the results that we found for level of expectations - which are lower for intermediate than for low-SES students (see Table 3). So, expectations act as a suppressor for this group rather than explaining part of the effect of social origin.

Table 5 focused on the reduction of the SES effect in absolute terms, however, it is potentially more interesting to look at relative differences or the percentage of the SES effect that is explained by primary versus secondary effects. In Figure 4, we show these mediation percentages in university enrollment probability for low versus high-SES students (panel (a)) and low versus intermediate-SES students (panel (b)).

The story is clearer for high-SES students in panel (a). Here, we see that achievement explains a larger percentage of the total SES effect in Germany (36 percent) than in the US (27 percent). Primary effects are, therefore, more important compared to secondary effects in Germany than in the US. This confirms H3(a). Concerning secondary effects, in the US, 12 percent of the remaining difference in enrollment between low- and high-SES students

\footnotetext{
${ }^{7}$ Significance of the mediation is calculated using the KHB method for the decomposition of direct and indirect effects (Karlson et al., 2012; Karlson and Holm, 2011).
} 
Figure 4: Decomposition of the Total SES Effect — Mediation Percentages

(a) High SES

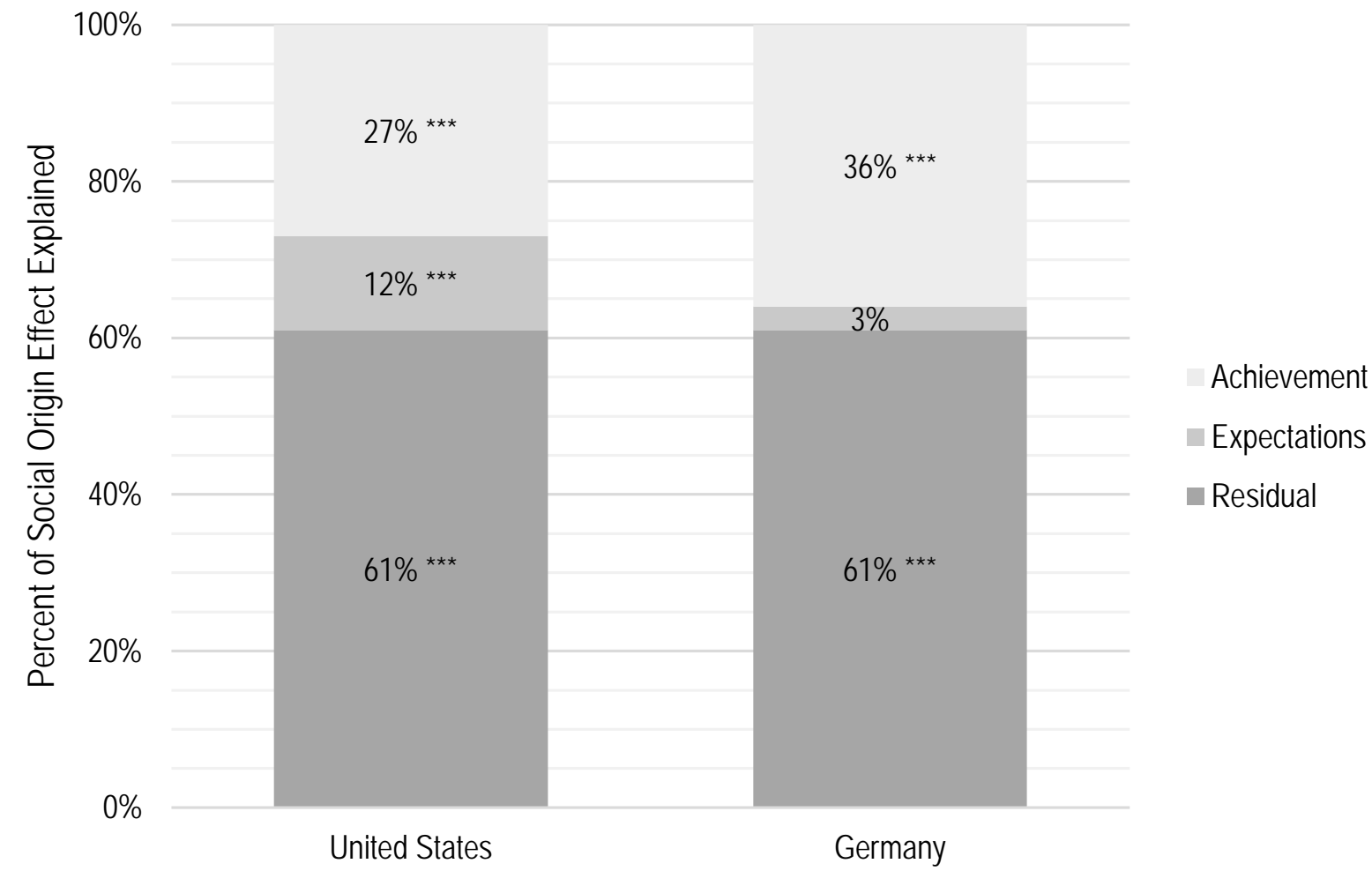

(b) Intermediate SES

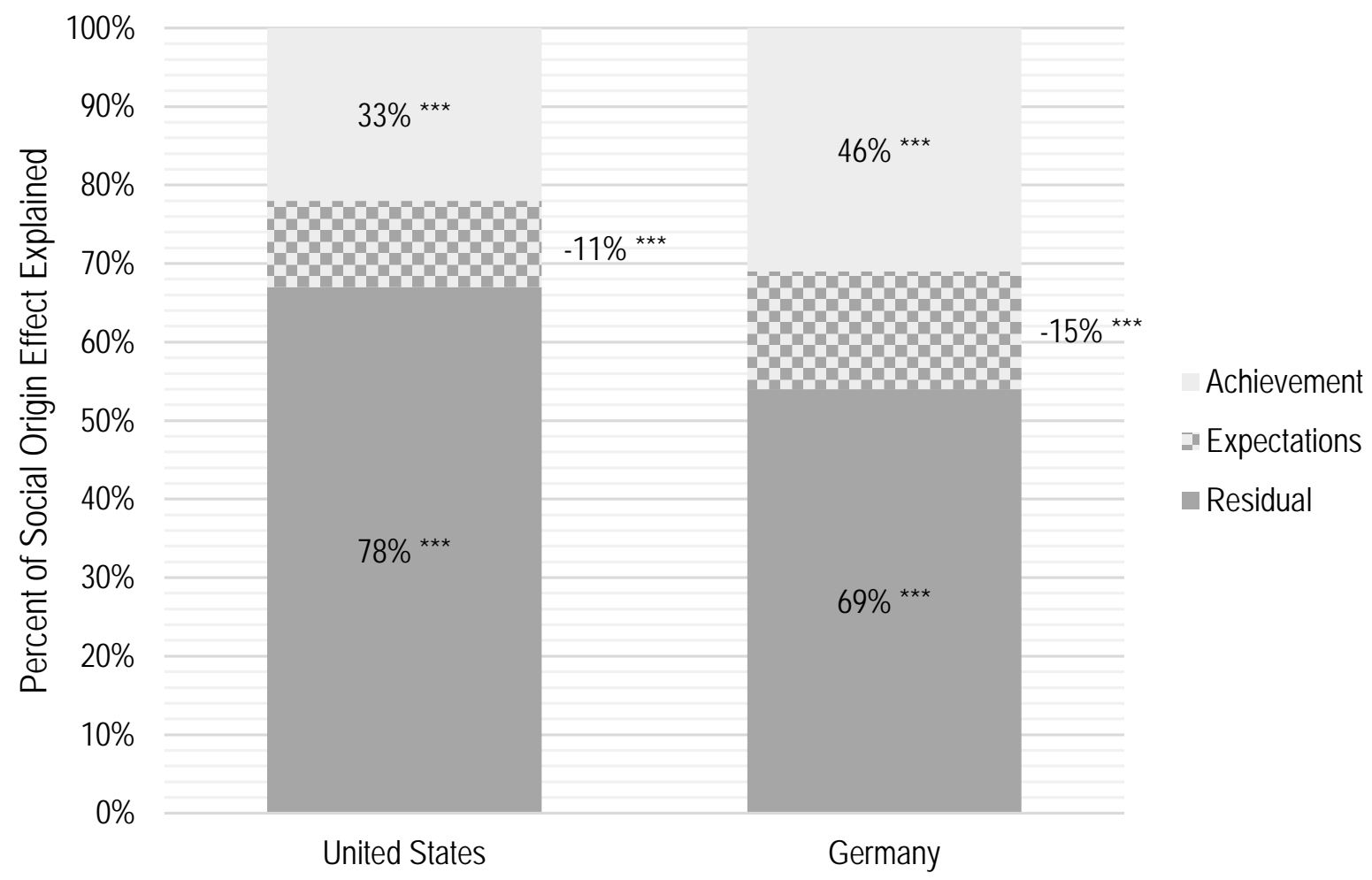

Mediation percentages based on Models in Table 5. Source: HSLS 2009 and NEPS SC4. Own Calculations. 
after accounting for achievement is explained by expectations. In Germany, this is only 3 percent (not significant). This means that H3(b) is not confirmed. Expectations contribute very little to the explanation of secondary effects in Germany while they do contribute more in the US.

For the difference between low- and intermediate-SES students in panel (b), we also find that achievement mediates a larger part of the total SES effect in Germany (46 percent) than in the US (33 percent). Also here, H3(a) is confirmed. Concerning expectations, the mediation percentage is negative. Expectations act as a suppressor as could be seen in Table 5. In Figure 4, this suppression effect is shown in the area in panel (b) that is shaded in two different colors. The suppression effect is larger in Germany ( -15 percent) than in the US (-11 percent). From this it can also be concluded, that expectations mediate less of the total origin effect in Germany than in the US, rejecting again H3(b). The residual inequality for intermediate versus low-SES students is higher in the US with 78 percent than in Germany with 69 percent of the total SES effect.

\section{Discussion and Conclusion}

We studied the relationship between students' social origin, their educational expectations and their higher education enrollment in two countries - the United States and Germany. We were interested in how students of different SES in these two countries compare concerning their levels of expectations and in how likely they are to realize high expectations by enrolling in university.

We found that in Germany students hold much lower levels of expectations than in the US. Also, low-SES students hold on average lower expectations than high-SES students in both countries. ${ }^{8}$ The overall SES gap in levels of expectations is larger in the US than in Germany for students that have similar levels of academic achievement. Concerning realization, we found that high-SES students are more likely to realize their high expectations in both countries than low-SES students even when they show similar levels of academic

\footnotetext{
${ }^{8}$ The intermediate-SES group holds even lower expectations than the low-SES group in both countries, a seemingly counterintuitive finding that might be explained by the different reference points these student groups take for developing their expectations.
} 
achievement. Concerning institutional settings, we found that students in the United States and Germany have a quite similar probability to translate their high expectations into university enrollment and also the SES gap in realization is similarly large in the US and Germany. Finally, we decomposed the total SES effect into different components. We found that in Germany, a larger share of the SES effect can be explained by achievement differences (primary effect) than in the US. We also showed that expectations do explain 12 percent of the remaining SES effect (secondary effect) in the US while this is only 3 percent (and not significant) in Germany. Overall, we can see that there is a substantial gap between expectations and their realization for all SES groups and both countries. It seems that it is not warranted to take the link between expectations and enrollment for granted as has been suggested by e.g., the Wisconsin model of status attainment (Sewell et al., 1969, 2004).

In particular, the found SES differences in levels of expectations and in realization are of substantive interest. Low-SES students are less likely to develop university expectations in their high school career. This SES gap in expectations has been described as realism (Buchmann and Park, 2009). However, it can also be characterized as self-fulfilling prophecy. Expectations adapt to the reality of opportunities that seem available to a student. Low-SES students more often get placed in low tracks and might therefore adjust their expectations downward more often even if their achievement is similar to high-SES students. Through their strong relationship with achievement, lower expectations can lead to lower effort and lower subsequent achievement. This increases SES gaps in expectations over time. While a certain dose of realism might be helpful for students to not get disappointed later on, such downward spirals have the potential to exacerbate social inequality in education. Additionally, even if they develop high expectations, low-SES students are less likely to realize them. Expectations, therefore act as a mechanism of social inequality in two ways. Very importantly, these findings cannot be explained by different levels of achievement, they hold true for students that perform on similar levels.

This study shows that it is not enough to encourage low-SES students to have high expectations. More has to be done so that they are also able to realize these expectations in order to close SES gaps in education. Research has shown for other mechanisms of 
educational inequality that low-SES students do benefit more from getting more "resources". For example, a higher level of cultural capital can help to increase social mobility for lowSES students (DiMaggio, 1982; De Graaf et al., 2000). Also high performance has stronger effects for low-SES students (Breen and Yaish, 2006; Bernardi and Boado, 2014) and so do more favorable time-discounting preferences (Breen et al., 2014). So, "equipping" low-SES students with higher levels of cultural capital or ability can potentially close the SES gap in education. With expectations, it seems to work differently. Even if low-SES students are equipped with high expectations, they benefit less from them than high-SES students. Therefore, increasing expectations alone cannot close social gaps in education. We can only speculate as to why this is the case. One reason could be that even if students have high expectations in high school, they still face more economic and psychological barriers on the way to higher education. These are processes that are also described by Morgan $(1998,2005)$ who focuses on how low-SES students are less stable in their commitment and expectations because of the mixed signals that they receive from their social environment. The influence of stability of expectations is also emphasized by Bozick et al. (2010). Furthermore, lowSES students, even with high expectations, might be more risk adverse on their way to higher education (Breen, 1999). In the face of barriers, they might more easily revert to safe trajectories in vocational education or two-year colleges.

Concerning the institutional context, we find that educational institutions seem to matter for setting the level of expectations that students develop. However, the rates of realization are fairly similar across countries. This is contrary to what has been found on the aggregate level (Buchmann and Park, 2009; Jerrim, 2014). Institutions seem not to matter a great deal for putting expectations into practice.

Finally, while SES differences in levels of expectations and in realization exist, they do not explain a large share of secondary effects of social origin — at least in Germany. In the German tracking system, social inequality is more strongly structured by achievement differences as shown with the higher share of primary effects. The remaining secondary effect is small and seems to run mostly through other factors than expectations. As students in Germany receive more salient achievement information it might also be the case that 
expectations are mostly shaped by achievement and do not contribute to inequality on top of it.

Finally, our study is faced with limitations that should be addressed by future research. First, we look at higher education enrollment about 2 to 3 years after high school completion. Final educational inequality might not be determined yet at this point in time. Due to delayed entry in and drop out from higher education, realization rates might still change. And it could be expected that these processes differ in the two countries and for different SES groups. Due to the high costs for college in the US, we can, for example, expect that low-SES students more often drop out. In Germany these differences might not be so severe. German students might more often translate high expectations into final attainment than students in the US. Therefore, it would be valuable to extend this research to a study of attainment once subsequent waves of the two data sets become available.

Second, it is difficult to form comparable SES categories across the two contexts. For example, it can be questioned if the two intermediate-SES groups consist of a comparable group of individuals in the two societies. This is a problem that is difficult to overcome in general but it could be alleviated by varying how SES is measured across the two countries, for example, by including other dimensions of SES such as income or occupational status. Similarly, also enrollment categories are hard to compare across countries. It remains difficult to specify if university enrollment in Germany and the US mean the same in terms of socioeconomic privilege and in terms of what groups in society have access to it. This is an inherent problem of direct country comparisons, however, that has no easy solution. We try to form groups of comparable sizes across the countries in order to look at comparable portions of society. This is, however, necessarily imperfect.

Third, it would be valuable to study the individual and institutional factors that help students realize their expectations - or keep them from doing so - to gain a deeper understanding of the mechanism. One interesting factor for the realization of expectations are post-secondary alternatives such as vocational education and training that might divert students away from higher education. 
Finally, we show associations between SES, achievement and expectations but we are not able to disentangle all processes between them in this paper. Achievement and expectations might reinforce each other. In order to study the process of expectation development more in detail, we would need longitudinal data that covers a larger part of the educational career. However, given that we place a focus on realization of expectations, we can at least conclude that the associations in this paper show that in order to close SES gaps in education we not only need to encourage students to have high expectations but we also need to remove other barriers in the educational system to make their high goals come true.

\section{References}

Alexander, K., R. Bozick, and D. Entwisle (2008). Warming Up, Cooling Out, or Holding Steady? Persistence and Change in Educational Expectations After High School. Sociology of Education 81(4), 371-396.

Allmendinger, J. (1989). Educational Systems and Labor Market Outcomes. European Sociological Review 5(3), 231-250.

Alon, S. (2009). The Evolution of Class Inequality in Higher Education: Competition, Exclusion, and Adaptation. American Sociological Review 74, 731-755.

Andrew, M. and J. Flashman (2017). School transitions, peer influence, and educational expectation formation: Girls and boys. Social Science Research 61, 218-233.

Andrew, M. and R. M. Hauser (2011). Adoption? Adaptation? Evaluating the Formation of Educational Expectations. Social Forces 90(2), 497-520.

Arum, R. and Y. Shavit (1995). Secondary Vocational Education and the Transition from School to Work. Sociology of Education 68(3), 187-204.

Baird, C. L., S. W. Burge, and J. R. Reynolds (2008). Absurdly Ambitious? Teenagers' Expectations for the Future and the Realities of Social Structure. Sociology Compass 2(3), 944-962. 
Beal, S. J. and L. J. Crockett (2010). Adolescents' occupational and educational aspirations and expectations: Links to high school activities and adult educational attainment. Developmental psychology 46(1), 258.

Bernardi, F. and H.-C. Boado (2014). Previous School Results and Social Background: Compensation and Imperfect Information in Educational Transitions. European Sociological Review 30(2), 207-217.

Blossfeld, H.-P. and D. J. von Maurice (2011). Education as a lifelong process. Zeitschrift für Erziehungswissenschaft 14(2), 19-34.

Bol, T. and H. G. Van de Werfhorst (2013). Educational Systems and the Trade-Off between Labor Market Allocation and Equality of Educational Opportunity. Comparative Education Review 57(2), 285-308.

Boudon, R. (1974). Education, Opportunity, and Social Inequality; Changing Prospects in Western Society. New York: Wiley.

Bozick, R., K. Alexander, D. Entwisle, S. Dauber, and K. Kerr (2010). Framing the future: Revisiting the place of educational expectations in status attainment. Social Forces 88(5), $2027-2052$.

Breen, R. (1999). Beliefs, Rational Choice and Bayesian Learning. Rationality and Society $11(4), 463-479$.

Breen, R. and J. O. Jonsson (2005). Inequality of Opportunity in Comparative Perspective: Recent Research on Educational Attainment and Social Mobility. Annual Review of Sociology 31(1), 223-243.

Breen, R., H. G. Van De Werfhorst, and M. M. Jæger (2014). Deciding under Doubt: A Theory of Risk Aversion, Time Discounting Preferences, and Educational Decisionmaking. European Sociological Review 30(2), 258-270.

Breen, R. and M. Yaish (2006). Testing the Breen-Goldthorpe model of educational decision making. In S. L. Morgan, D. B. Grusky, and G. S. Fields (Eds.), Frontiers of Research 
in Sociology and Economics: Mobility and Inequality., pp. 232-258. Stanford: Stanford University Press.

Buchmann, C. and B. Dalton (2002). Interpersonal Influences and Educational Aspirations in 12 Countries: The Importance of Institutional Context. Sociology of Education 75(2), $99-122$.

Buchmann, C. and H. Park (2009). Stratification and the formation of expectations in highly differentiated educational systems. Research in Social Stratification and Mobility 27(4), $245-267$.

Chmielewski, A. K. (2017). Social inequality in educational transitions under different types of secondary school curricular differentiation. In I. School and R. K. Silbereisen (Eds.), Pathways to Adulthood: Educational Opportunities, Motivation and Attainment in Times of Social Change, pp. 51-72. London: UCL IoE Press.

Clark, B. R. (1960). The "Cooling-Out" Function in Higher Education. American Journal of Sociology 65(6), 569-576.

De Graaf, N. D., P. M. De Graaf, and G. Kraaykamp (2000). Parental cultural capital and educational attainment in the Netherlands: A refinement of the cultural capital perspective. Sociology of education 73(2), 92-111.

DiMaggio, P. (1982). Cultural Capital and School Success: The Impact of Status Culture Participation on the Grades of U.S. High School Students. American Sociological Review 47(2), 189-201.

Domina, T., A. Conley, and G. Farkas (2011). The Link between Educational Expectations and Effort in the College-for-all Era. Sociology of Education 84(2), 93-112.

Dupriez, V., X. Dumay, and A. Vause (2008). How Do School Systems Manage Pupils' Heterogeneity? Comparative Education Review 52(2), 245-273. 
Duru-Bellat, M., A. Kieffer, and D. Reimer (2008). Patterns of Social Inequalities in Access to Higher Education in France and Germany. International Journal of Comparative Sociology 49(4-5), 347-368.

Finger, C. (2016). Institutional constraints and the translation of college aspirations into intentions -Evidence from a factorial survey. Research in Social Stratification and Mobility $46,112-128$.

Goyette, K. A. (2008). College for some to college for all: Social background, occupational expectations, and educational expectations over time. Social Science Research 37(2), $461-484$.

Grodsky, E. and M. T. Jones (2007). Real and imagined barriers to college entry: Perceptions of cost. Social Science Research 36(2), 745-766.

Hanson, S. L. (1994). Lost Talent: Unrealized Educational Aspirations and Expectations among U.S. Youths. Sociology of Education 67(3), 159-183.

Jackson, M. (Ed.) (2013). Determined to Succeed?: Performance versus Choice in Educational Attainment. Stanford: Stanford University Press.

Jacob, M. and N. Tieben (2009). Social Selectivity of Track Mobility in Secondary Schools. European Societies 11(5), 747-773.

Jerrim, J. (2014). The Unrealistic Educational Expectations of High School Pupils: Is America Exceptional? The Sociological Quarterly 55(1), 196-231.

Kao, G. and M. Tienda (1998). Educational Aspirations of Minority Youth. American Journal of Education 106(3), 349-384.

Karlson, K. B. (2015). Expectations on Track? High School Tracking and Adolescent Educational Expectations. Social Forces 94(1), 115-141.

Karlson, K. B. and A. Holm (2011). Decomposing Primary and Secondary Effects: A New Decomposition Method. Research in Social Stratification and Mobility 29(2), 221-237. 
Karlson, K. B., A. Holm, and R. Breen (2012). Comparing Regression Coefficients Between Same-sample Nested Models Using Logit and Probit: A New Method. Sociological Methodology 42(1), 286-313.

Kerckhoff, A. C. (1976). The Status Attainment Process: Socialization or Allocation? Social Forces 55(2), 368-381.

Kerckhoff, A. C. (1977). The Realism of Educational Ambitions in England and the United States. American Sociological Review 42(4), 563-571.

Morgan, S. L. (1998). Adolescent educational expectations: Rationalized, fantasized or both? Rationality and Society 10(2), 131-162.

Morgan, S. L. (2005). On the Edge of Commitment: Educational Attainment and Race in the United States. Stanford: Stanford University Press.

Parker, P. D., J. Jerrim, I. Schoon, and H. W. Marsh (2016). A Multination Study of Socioeconomic Inequality in Expectations for Progression to Higher Education: The Role of Between-School Tracking and Ability Stratification. American Educational Research Journal 53(1), 6-32.

Reimer, D. and R. Pollak (2010). Educational Expansion and Its Consequences for Vertical and Horizontal Inequalities in Access to Higher Education in West Germany. European Sociological Review 26(4), 415-430.

Reynolds, J. R., M. Stewart, R. Macdonald, and L. Sischo (2006). Have Adolescents Become Too Ambitious? High School Seniors' Educational and Occupational Plans, 1976 to 2000. Social Problems 53(2), 186-206.

Rosenbaum, J. E. (2001). Beyond College For All: Career Paths for the Forgotten Half. New York: Russell Sage Foundation.

Roth, T. (2017). Interpersonal influences on educational expectations: New evidence for Germany. Research in Social Stratification and Mobility 48, 68-84. 
Sewell, W. H., A. O. Haller, and A. Portes (1969). The Educational and Early Occupational Attainment Process. American Sociological Review 34(1), 82-92.

Sewell, W. H., R. M. Hauser, K. W. Springer, and T. S. Hauser (2004). As We Age: A Review of the Wisconsin Longitudinal Study, 1957-2001. Research in Social Stratification and Mobility 20, 3-111.

Sewell, W. H. and V. P. Shah (1968). Social Class, Parental Encouragement, and Educational Aspirations. American Journal of Sociology 73(5), 559-572.

Shavit, Y. and H.-P. Blossfeld (1993). Persistent Inequality: Changing Educational Attainment in Thirteen Countries. Boulder, CO: Westview Press.

Shavit, Y. and W. Müller (1998). From School to Work. A Comparative Study of Educational Qualifications and Occupational Destinations. Oxford: Clarendon Press.

Shavit, Y. and W. Müller (2000). Vocational Secondary Education. European Societies 2(1), $29-50$.

US Department of Education (2009). High School Longitudinal Study. https://nces.ed.gov/surveys/hsls09/contact.asp.

US Department of Education (2019). Gaining Early Awareness and Readiness for Undergraduate Programs (GEAR UP). https://www2.ed.gov/programs/gearup/index.html.

Von Hippel, P. T. (2007). Regression with Missing Ys: An Improved Strategy for Analyzing Multiply Imputed Data. Sociological Methodology 37, 83-117. 


\section{Appendix}

\section{A Educational Systems of Germany and the United States}

Figure A1 shows a schematic overview of the tracking systems in the US and in Germany. We can see that the German system is much more differentiated at the middle and high school level. While in the US all students follow the same trajectory (with some variations across states and regions), in Germany students are placed into different ability tracks from (mostly) fifth grade onwards. At the level of higher education, both countries broadly offer two different types of institutions.

\section{B Imputation Diagnostics}

We use multiple imputation via chained equations to complete missing values on the independent variables and create 20 imputed data sets. The imputation model includes all variables from the main analysis including the dependent variables. Additionally, we include further auxiliary variables to improve the imputation. For the US, those variables are: expectations at age 15, mathematics competence at age 17, birth year, employment status of both parents, household size, and family income. For Germany, the auxiliary variables are: expectations at age 15, mathematics competence at age 18, birth year, occupational status of both parents, number of books at home, household size, number of siblings, and family income.

Table A1 and Table A2 show all imputed independent variables that are used in the main analysis with their respective imputation models as well as counts and percentages of imputed cases. For the HSLS data (United States), the share of imputed cases ranges from 8.8 percent for mathematics competence to 28.6 percent for parental education. For the German NEPS data, the share of imputed cases ranges from 0.5 percent for gender to 67.2 percent for expectations at age 17 . 
Figure A1: Educational Systems in the United States and Germany (Simplified)
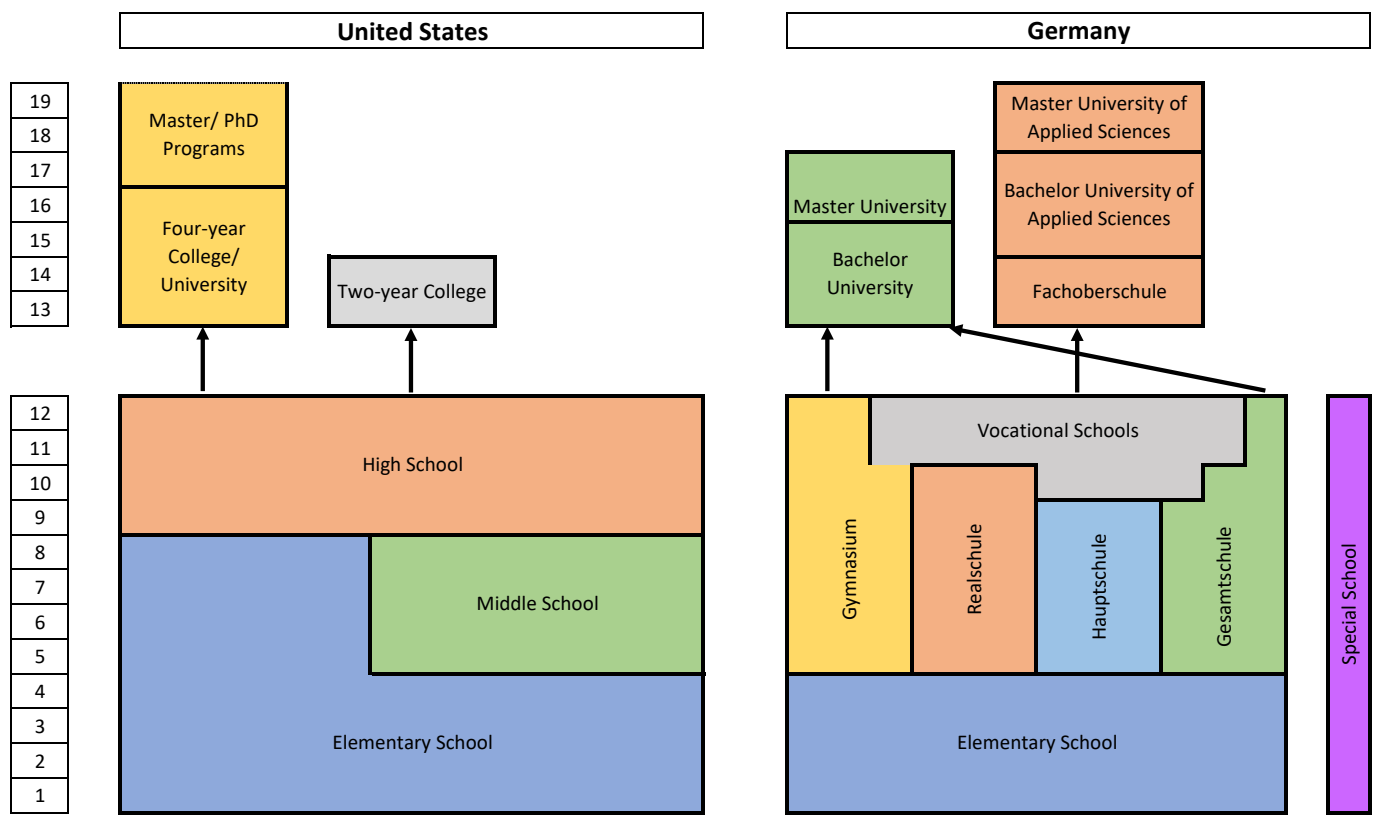

Table A1: Imputed and Complete Observations (HSLS)

\begin{tabular}{llcrcc}
\hline Model & Variable & Complete & Imputed & Perc. Imp. & Total \\
\hline ologit & Parents' Educ. (3-cat) & 16,782 & 6,721 & $28.6 \%$ & 23,503 \\
logit & High Expectations at 17 & 18,488 & 5,015 & $21.3 \%$ & 23,503 \\
pmm & Mathematics Competence at 15 & 21,444 & 2,059 & $8.8 \%$ & 23,503 \\
\hline
\end{tabular}

The remaining independent variables, gender and race, do not have missing values.

Source: HSLS 2009. Own calculations.

Table A2: Imputed and Complete Observations (NEPS)

\begin{tabular}{llrrrc}
\hline Model & Variable & Complete & Imputed & Perc. Imp. & Total \\
\hline pmm & Parents' Educ. (3-cat) & 13,156 & 3,269 & $19.9 \%$ & 16,425 \\
logit & High Expectations at 17 & 5,388 & 11,037 & $67.2 \%$ & 16,425 \\
pmm & Mathematics Competence at 15 & 14,523 & 1,902 & $11.6 \%$ & 16,425 \\
logit & Female & 16,341 & 84 & $0.5 \%$ & 16,425 \\
logit & Father Born Abroad & 14,926 & 1,499 & $9.1 \%$ & 16,425 \\
logit & Mother Born Abroad & 15,250 & 1,175 & $7.2 \%$ & 16,425 \\
\hline
\end{tabular}

Source: NEPS SC4. Own calculations. 
Table A3: Level of Expectations — No Achievement Controls

\begin{tabular}{|c|c|c|}
\hline & United States (HSLS) & GERMANY (NEPS) \\
\hline \multicolumn{3}{|c|}{ Parents' Education $($ Ref $=$ Low $)$} \\
\hline \multirow[t]{2}{*}{ Intermediate } & -0.003 & 0.0004 \\
\hline & $(0.01)$ & $(0.02)$ \\
\hline \multirow[t]{2}{*}{ High } & $0.28^{* * *}$ & $0.15^{* * *}$ \\
\hline & $(0.01)$ & $(0.02)$ \\
\hline \multirow[t]{2}{*}{ Female } & $0.08^{* * *}$ & $0.08^{* * *}$ \\
\hline & $(0.01)$ & $(0.02)$ \\
\hline \multicolumn{3}{|c|}{ Race/Ethnicity (Ref = White) } \\
\hline \multirow[t]{2}{*}{ Asian } & $0.08^{* * *}$ & \\
\hline & $(0.01)$ & \\
\hline \multirow[t]{2}{*}{ Black } & 0.02 & \\
\hline & $(0.01)$ & \\
\hline \multirow[t]{2}{*}{ Hispanic } & $-0.04^{* *}$ & \\
\hline & $(0.01)$ & \\
\hline \multirow[t]{2}{*}{ Other } & -0.002 & \\
\hline & $(0.01)$ & \\
\hline \multirow[t]{2}{*}{ Parent Born Abroad } & & $-0.05^{* *}$ \\
\hline & $(0.02)$ & \\
\hline \multirow[t]{2}{*}{ Constant } & $0.55^{* * *}$ & $0.30^{* * *}$ \\
\hline & $(0.01)$ & $(0.02)$ \\
\hline R Squared & 0.11 & 0.03 \\
\hline Observations & 17,201 & 9,044 \\
\hline
\end{tabular}

Standard errors in parentheses.

Significance: ${ }^{*} p<0.05,{ }^{* *} p<0.01,{ }^{* * *} p<0.001$

Source: HSLS 2009 and NEPS SC4. Own calculations.

\section{Analyses without Achievement Controls}

This section shows all analyses without achievement controls. In these analyses, we do not look at expectations as a mechanism behind secondary effects but we also let them pick up primary effects (i.e., achievement differences). Table A3 shows the analysis where expectations are the dependent variable. Figure A2 shows the predicted levels of expectations for the different SES groups by country. Table A4 shows the analysis of university enrollment. Finally, Figure A3 shows the predicted enrollment for different levels of parental SES for Germany and the US. How the results in these tables and figures differs from those with achievement controls is discussed in the section "A note on achievement" in the main text. 
Figure A2: Predicted Levels of Expectations — No Achievement Controls

(a) United States

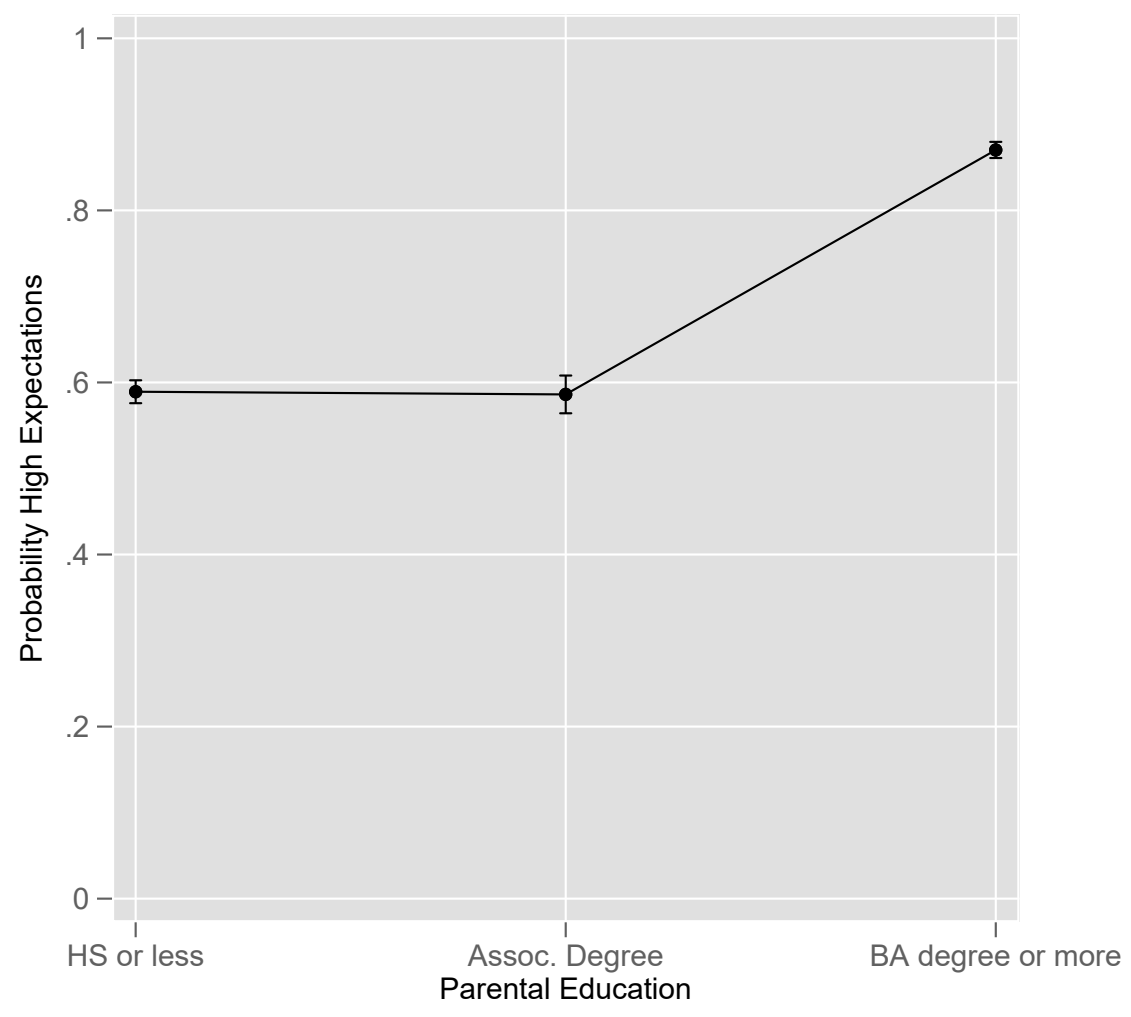

(b) Germany

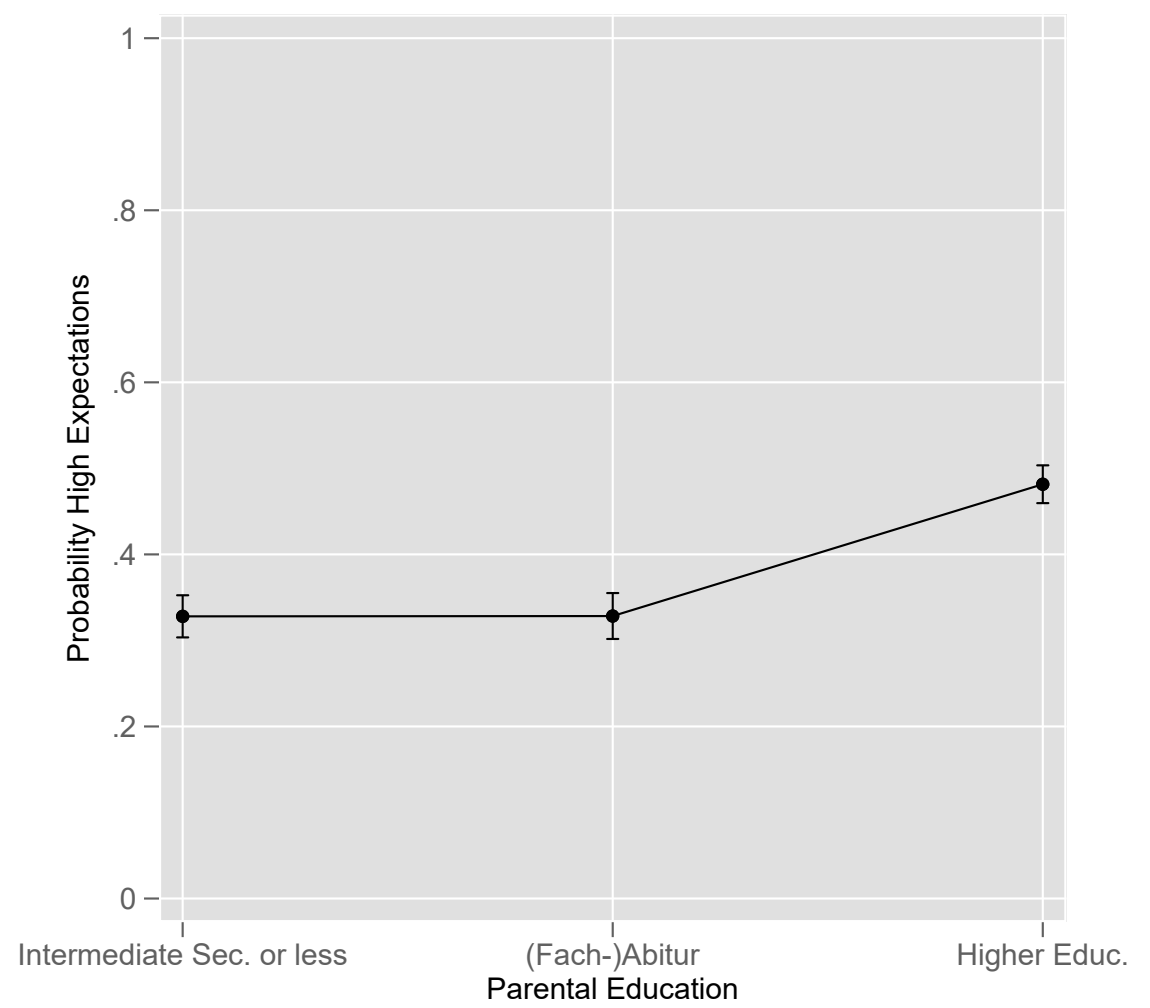

Predicted Probabilities based on Model 2 in Table A3.

Source: HSLS 2009 and NEPS SC4. own calculations. 
Table A4: Realization of Expectations - No Achievement Controls

\begin{tabular}{|c|c|c|c|c|}
\hline & \multicolumn{2}{|c|}{ United States (HSLS) } & \multicolumn{2}{|c|}{ GERMANY (NEPS) } \\
\hline & $(1)$ & $(2)$ & $(1)$ & $(2)$ \\
\hline High Expectations (ref=Low) & $\begin{array}{l}0.31^{* * *} \\
(0.01)\end{array}$ & $\begin{array}{l}0.25^{* * *} \\
(0.01)\end{array}$ & $\begin{array}{l}0.29^{* * *} \\
(0.01)\end{array}$ & $\begin{array}{l}0.20^{* * *} \\
(0.01)\end{array}$ \\
\hline \multicolumn{5}{|l|}{ Parents' SES (ref=Low) } \\
\hline Intermediate & $\begin{array}{l}0.09^{* * *} \\
(0.01)\end{array}$ & $\begin{array}{l}0.05^{* * *} \\
(0.01)\end{array}$ & $\begin{array}{l}0.13^{* * *} \\
(0.01)\end{array}$ & $\begin{array}{l}0.08^{* * *} \\
(0.01)\end{array}$ \\
\hline High & $\begin{array}{l}0.32^{* * *} \\
(0.01)\end{array}$ & $\begin{array}{l}0.16^{* * *} \\
(0.02)\end{array}$ & $\begin{array}{l}0.23^{* * *} \\
(0.01)\end{array}$ & $\begin{array}{l}0.15^{* * *} \\
(0.01)\end{array}$ \\
\hline \multicolumn{5}{|c|}{ High Expectations $\times$ Parents' SES $($ ref $=$ Low $)$} \\
\hline$\times$ Intermediate SES & & $\begin{array}{l}0.07^{* * *} \\
(0.02)\end{array}$ & & $\begin{array}{l}0.16^{* * *} \\
(0.03)\end{array}$ \\
\hline$\times$ High SES & & $\begin{array}{l}0.21^{* * *} \\
(0.02)\end{array}$ & & $\begin{array}{l}0.20^{* * *} \\
(0.02)\end{array}$ \\
\hline Female & $\begin{array}{l}0.06^{* * *} \\
(0.01)\end{array}$ & $\begin{array}{l}0.06^{* * *} \\
(0.01)\end{array}$ & $\begin{array}{l}0.03^{* *} \\
(0.01)\end{array}$ & $\begin{array}{l}0.02^{* *} \\
(0.01)\end{array}$ \\
\hline \multicolumn{5}{|l|}{ Race/Ethnicity (Ref $=$ White $)$} \\
\hline Asian & $\begin{array}{l}0.11^{\text {*** }} \\
(0.01)\end{array}$ & $\begin{array}{l}0.11^{* * *} \\
(0.01)\end{array}$ & & \\
\hline Black & $\begin{array}{c}-0.08^{* * *} \\
(0.01)\end{array}$ & $\begin{array}{c}-0.08^{* * *} \\
(0.01)\end{array}$ & & \\
\hline Hispanic & $\begin{array}{c}-0.06^{* * *} \\
(0.01)\end{array}$ & $\begin{array}{c}-0.05^{* * *} \\
(0.01)\end{array}$ & & \\
\hline Other & $\begin{array}{c}-0.06^{* * *} \\
(0.01)\end{array}$ & $\begin{array}{c}-0.05^{* * *} \\
(0.01)\end{array}$ & & \\
\hline Parent Born Abroad & & & $\begin{array}{c}-0.00 \\
(0.01)\end{array}$ & $\begin{array}{c}0.00 \\
(0.01)\end{array}$ \\
\hline Constant & $\begin{array}{l}0.02^{* *} \\
(0.01)\end{array}$ & $\begin{array}{l}0.06^{* * *} \\
(0.01)\end{array}$ & $\begin{array}{c}-0.00 \\
(0.01)\end{array}$ & $\begin{array}{l}0.03^{* * *} \\
(0.01)\end{array}$ \\
\hline R squared & 0.31 & 0.32 & 0.26 & 0.27 \\
\hline Observations & 17,201 & 17,201 & 9,044 & 9,044 \\
\hline
\end{tabular}

Standard errors in parentheses.

Significance: ${ }^{*} p<0.05,{ }^{* *} p<0.01,{ }^{* * *} p<0.001$

Source: HSLS 2009 and NEPS SC4. Own calculations. 
Figure A3: Predicted Probabilities University Enrollment for Students with different Levels of Expectations at Age 17 from different SES groups — No Achievement Controls

(a) United States

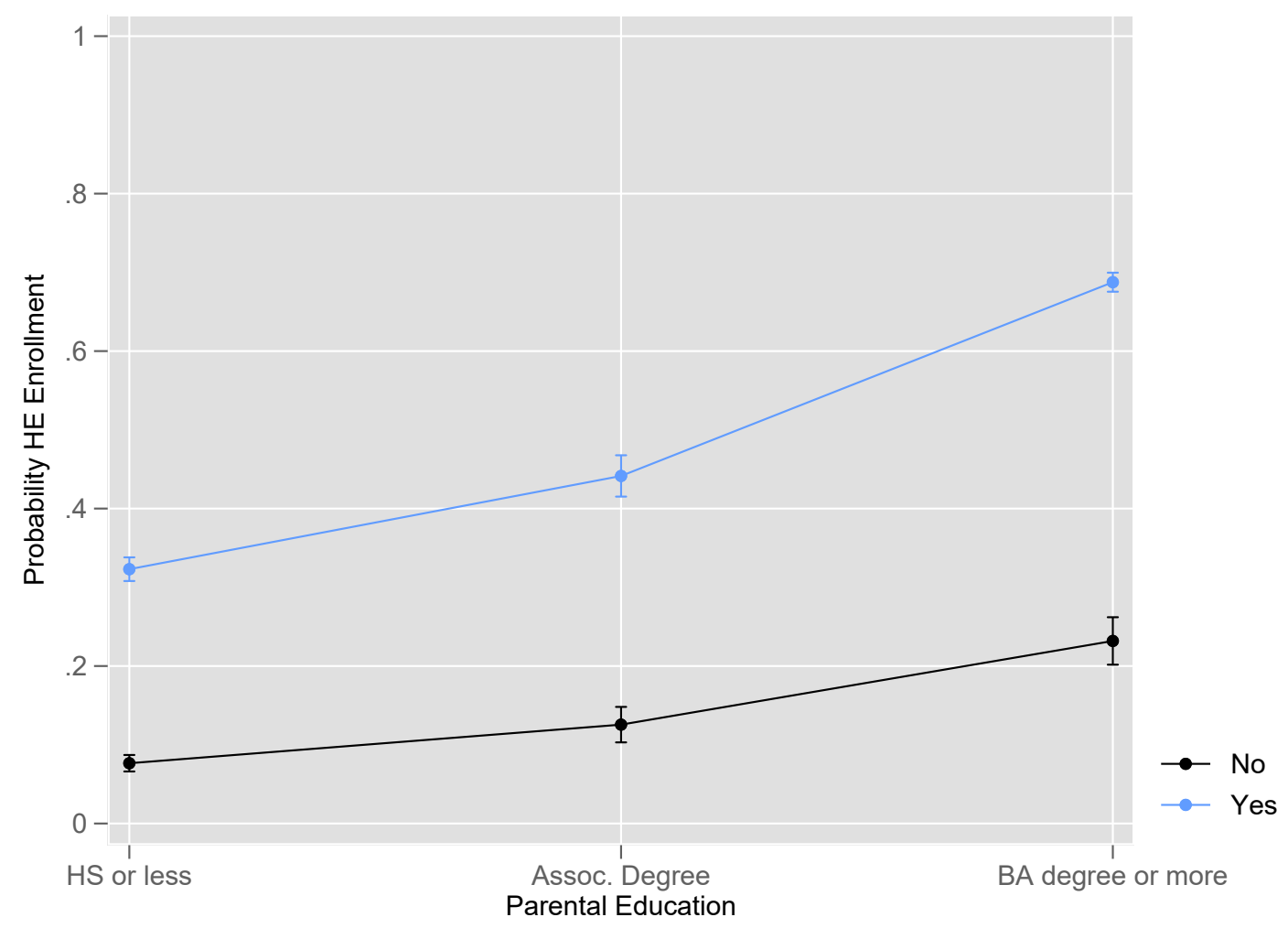

(b) Germany

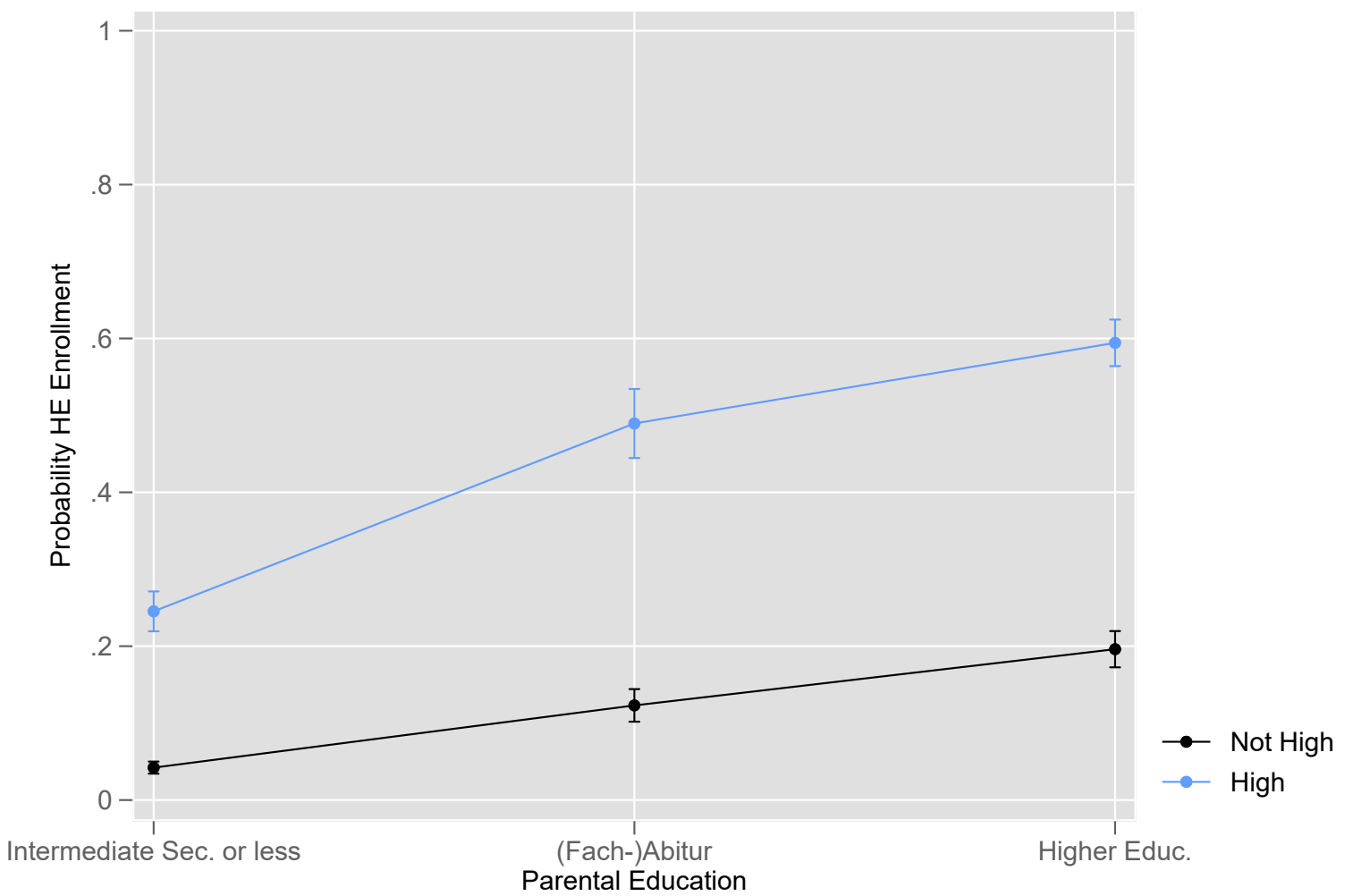

